\title{
Financial Bubbles, Common Knowledge and Alternative Accounting Regimes: An Experimental Analysis of Artificial Spot Security Markets* Accounting for or from the Market?
}

LARRY BENSIMHON

Laboratoire Interdisciplinaire de Rechrche en Sciences de l'Action (LIRSA), Conservatoire National des ARTS et MÉtiers

\author{
YURI BIONDI ${ }^{\dagger}$ \\ Centre National de LA RECHERChe SCIENTIFIOUe \\ and ESCP EUROPE
}

\begin{abstract}
We experimentally explore how common knowledge provided by accounting systems affects investors' decision and shapes the formation of security prices over time. We design alternative accounting structures and run experiments in artificial security markets framed by these structures. In sessions where investors receive exogenous accounting information about ultimate earnings, prices converge to the fundamental levels derived from those earnings through backward induction. Accounting plays a role for the market. In sessions where investors receive endogenous accounting information about earnings that are linked to the ongoing clearing price of the security, market price levels and paths become indeterminate and lose earnings anchor; investors tend to form their expectations of future prices by forward, not backward, induction. Accounting plays its role from the market, and loses its relevance in financial decision-making. These laboratory results suggest that accounting information and its overarching structure are important to prevent market exuberance, excess volatility and the formation of financial bubbles. They further have relevant effects on market allocative efficiency, and revenue and wealth distribution among investors.
\end{abstract}

JEL Classification: G12; C9; D4; M41; M48; G1

Key Words: Share Price Bubbles; Market Exuberance; Excess Volatility;

Short-term Investors; Backward Induction; Forward Induction;

Experimental Financial Markets; Fair Value; Mark-to-Market;

Accounting Regime

\footnotetext{
* Acknowledgments: We thank Shyam Sunder (Yale University) for his insightful suggestions and longstanding encouragement. We also thank Maxim Frolov (LEEP of Paris) for his committed programming expertise and technical support. Usual disclaimer applies.

Disclosures: The project was funded by a grant of a French public institute, the Maison des Sciences de l'Homme - Paris Nord (MSH-PN). The experiment was programmed and conducted with the software $\mathrm{z}$-Tree (Fischbacher 2007).

† Corresponding Author: Address ESCP Europe, 79, Avenue de la République 75011 Paris, FRANCE. Telephone +33

(0) 149232000 E-mail yuri.biondi@gmail.com website http://yuri.biondi.free.fr/
}

Received March 14, 2013; available online May 16, 2013 (Advance publication by J-STAGE)

DOI: 10.11640/tjar.3.2013.02 


\section{Introduction}

What is a financial bubble? Popular press and wisdom do associate bubbling with abrupt changes in security market prices over time. A bubble occurs when market prices rise intensely and rapidly and drop thereafter, rapidly and intensely as well. Academic literature has provided several definitions of financial bubbling, and insightful analyses of their formation over time. For example, Smith et al. (1988) observed that artificial market prices consistently differed from the fundamental value of the security, and labeled those price patterns as bubbles or crashes. King et al. (1993) defined artificial market bubbles as "trade at high volumes at prices that are considerably at variance from intrinsic values". From this perspective, bubbling is then related to market volatility and market exuberance. ${ }^{1}$

In fact, econometric tests of bubbling are confronted with difficulties in defining and estimating the fundamental value of reference, and other theoretical and statistical issues. Fundamental values are somehow defined on the basis of the series of future dividends linked to holding securities when dividends are paid. In particular, tests are forced to assess all alternative models on the only market price series that has actually occurred over time. However, the alternative series of market prices that would have happened under a different set of conditions can be imagined, but not empirically tested and comparatively assessed. From this viewpoint, experimental analysis of artificial markets appears to be well suited to assess the formation of bubbles and their evolution over time (see Ball and Holt (1998) and Davis and Holt (1993), chapters 1, 3, and 7 for an introduction). Experimental design allows controlling for conditions, including the series of fundamental values, while several market price patterns can be generated under alternative experimental treatments. Experimental economic literature has investigated bubbling under various sets of conditions. Generally speaking, experimental literature points out limited information about present or future investors' expectations; the existence of irrational present or future investors; or the rational inclusion of the bubble term not linked to future dividends at all. Plott (1989), Holt (1995), and Sunder (1995) provide literature surveys on artificial financial markets.

In particular, Smith et al. (1988) paved the way to analyze bubbling under conditions of common knowledge. They designed a security market with three adjustment dynamics: the process that describes changes in the security's dividend value; the evolution of agents' price expectations; and the security's price adjustments. The dividend structure and actual dividend draws were the same for every trader in the market, and this information was common knowledge. Experimental results showed that a common dividend, and common knowledge thereof were insufficient to align market prices with fundamental values. These authors and Lei, Noussair and Plott (2001) provided alternative explanations of such bubbling based on the formation of agents' expectations in those markets. The former conjectured that investors may conduct transient speculative trades aiming at selling the security to others at higher prices. The latter rejected this conjecture by showing that bubbles arise when investors cannot engage in speculative trades, attributing bubbling to errors in traders' decision-making.

Smith et al. (2000) designed a setting where a single dividend was paid out at the end of the time horizon. The dividend was random but its distribution was common knowledge. This

\footnotetext{
${ }^{1}$ See Brunnermeier (2001), Camerer (1989) and Stiglitz (1990) for broad overviews.
} 
setting consistently helped to align prices and the expected value of the single dividend draw. Noussair, Robin and Ruffieux (2001) further refined this experimental analysis by distinguishing between single dividend final payout and constant fundamental value as market stabilizing devices, deciding in favor of the former. The dividend process, the number of periods, and the existence and amount of the final buyout were common knowledge to all subjects. Moreover, Kirchler (2009) implemented experimental asset markets with fluctuating fundamental values following a stochastic process that had a positive drift and a large standard deviation.

Starting from Smith et al. (1988) and Lei et al. (2001), Hirota and Sunder (2007) designed two alternative sets of artificial markets that are distinguished by featuring final payouts: from one hand, investors exit the market by receiving an exogenously specified dividend; from another hand, they exit the market by receiving the prices that are endogenously generated throughout the session. Bubbles did not occur in the former treatment, while they did in the latter, where prices lost dividend anchors and price levels and paths became indeterminate. They conjectured about investors' horizon to explain this result. Those horizons would be long-term in the former, and short-term in the latter treatment, justifying whether bubbles occur or not. In fact, their design does not denote explicitly investors' horizons, which are not under direct experimental control, but it does denote the payout structure and the common knowledge of it. A collective device is then introduced having two alternative regimes: under the former regime, the device paid out a stable value of reference; under the latter regime, the device paid out a shifting value that fluctuates along with the market price over time.

This regime-based setting is path-breaking in putting forth the idea that bubbles can occur because of lack of "knowledge, beliefs and coordination devices necessary for prices to coincide with the fundamental values" (Hirota and Sunder 2007, p. 1877, italics added). Theoretically speaking, this understanding of the formation of share prices over time stresses the share Exchange as a coordinating mechanism among investors. Tirole (1982) showed that coordination lack between investors' expectations and plans can justify the occurrence of bubbles. Both Abreu and Brunnermeier (2003), and Azariadis (1981) stressed coordination failures to explain bubbling. In particular, the need of coordination devices points to the implications of the institutional architecture that frames and enables the working of the market over time (Frydman 1982). ${ }^{2}$ Together with investors' knowledge and beliefs (related to their expectations and horizons), this architecture contributes to determine the evolution of the market price series and its connection with fundamental values of reference over time. In all treatments, investors received two distinctive collective signals from this architecture: one from the collective device fixing the security final payout, and another one from the market price system that generates current security prices over time through ongoing bids and asks. Therefore, investors were confronted to two distinctive ways of earning money: designed final payouts and capital gains (losses) from trading. Furthermore, their shared information set, i.e., their common knowledge was jointly composed by market-driven (the history of market prices and returns) and firmspecific information (the history of enterprise payouts and returns), as early claimed by Fama and French (1992).

The working of that collective device fixing final payout relates to the role plaid by the accounting system of the business firm in the share market pricing process. Like this collective

\footnotetext{
2 This may be seen as an application of incentive regulation to the financial market microstructure and working (Laffont and Tirole 1993).
} 
device, the accounting system provides signals of fundamental information about financial performance and position of the business firm that has issued the traded shares (Shubik 1993). This information is somehow related to the fundamental value of those securities (Lintner 1956) and is common knowledge among all investors (Sunder 2002). In particular, the accounting system design is an integral part of the institutional architecture that defines share payouts: From the monetary viewpoint, accounting identifies the financial performance accrued and eventually distributed to shareholders (which are investors who hold shares at the moment of dividend distribution); from the cognitive viewpoint, it declares a collective signal of fundamental performance of the business firm.

Our paper aims at investigating security market bubbling under alternative accounting regimes. We experimentally explore how common knowledge provided by accounting systems affects investors' decisions and shapes the ongoing formation of security prices. Previous experimental evidence proved that common fundamental value is not sufficient to prevent bubbling, and that the design of the collective device labeled "accounting system" hereafter contributes to investors' decision-making and shapes the security market pricing over time. On this basis, we design alternative accounting structures and run experiments in artificial security markets framed by these structures.

Generally speaking, two distinctive families of accounting models exist, one based on fair value accounting, another one on historical cost accounting (Anthony 2004, p. 25). They respectively perform:

- The collective provision of firm-specific information that follows the information provided by the market (so-called fair value accounting model) ${ }^{3}$

- The collective provision of firm-specific accounting information that constitutes an autonomous source of information (so-called historical cost accounting model).

Under the first regime, the accounting model is expected to replicate the market signal over time. This corresponds to a pure fair value accounting that assumes a perfect alignment of accounting information with current market price. The accounting system adopts then a perfect stock method providing fundamental information that relies on the most updated market price available (Penman 2011).

Under the second regime, the accounting model is expected to provide an exogenous time series that is independent from the market. This corresponds to a pure historical cost accounting that determines the accrued performance over the period independently from market conditions. The accounting system adopts then a perfect flow method providing fundamental information jointly composed by exogenous positive and negative flows (Biondi 2011).

We run two series of comparable market experiments under both accounting regimes, in order to test whether and under which accounting regime security prices better align with fundamental values of reference; whether accounting regimes reduce the likelihood and intensity of bubbles; whether accounting regimes improve on the allocative efficiency of the market; and whether and how accounting regimes shape the distribution of incomes generated by market

\footnotetext{
${ }^{3}$ We consider "mark-to-market" accounting and "fair value" accounting synonymously. While the first approach implies the use of observable market prices to measure the value of every asset and liability, the second approach includes the recourse to observable and unobservable inputs to reproduce that value.
} 
trading.

According to our experimental results, in historical cost accounting sessions where investors received exogenous accounting information about ultimate earnings, prices converge to the fundamental levels derived from those earnings through backward induction. Accounting plays a role for the market. In fair value accounting sessions where investors receive endogenous accounting information about earnings that are linked to the ongoing clearing price of the share, price levels and paths become indeterminate and lose earnings anchor; investors tend to form their expectations of future prices by forward, not backward, induction. Accounting plays its role from the market, and loses any stabilizing property and its relevance in financial decision-making. These laboratory results suggest that accounting information and its overarching regime are important to prevent market exuberance, excess volatility and the formation of bubbles. Historical cost accounting structures further appear to improve on market allocative efficiency, and have positive effects in reducing revenue and wealth dispersion among investors.

The rest of the paper is organized as follows. We describe experimental design and the featuring conditions for determinants of the market price process to be investigated: individual investors, security Exchange microstructure, and alternative accounting regimes. On this basis, we provide economic analysis of our experimental results, summarized on five different results concerned with the quality of market pricing process by technical and fundamental approach, the formation of individual expectations and bidding/asking strategies, the allocative efficiency and the income and wealth distribution generated by that process. Each result is accompanied by a specific appendix providing graphical and numerical analysis thereof. A brief summary concludes.

\section{Experimental design}

We organize artificial double auction markets for trading units of securities on a computer network in a laboratory. All experiments were run in the Laboratory of Experimental Economics of Paris (LEEP), between 2 and 5 August 2011. A fresh set of subjects were recruited for each of the nine sessions, and none had participated in any previous research experiments on security markets. Recruiting mailing list included, but was not limited to, undergraduate and graduate students, which were 67 (69\%) on 97 participants. Subjects' age ranged between 18 and 72 years old; mean (median) age was 28 (24) years old. Male subjects were 36 (37\%). Participants to the experiments were randomly assigned to different treatments retained for the procedure. To be recruited, subjects were informed that the experiment consisted to make investment decisions on artificial financial markets.

Every session comprises a series of 15 periods of 3 minutes each, followed by 1 or 2 minutes of paperwork (the next trading period did not start up unless all investors agree with by clicking on their button). Before each session, participants read the instructions by themselves (see Appendix.Game). Thereafter, instructors review again and explained these instructions to the participants, which were further trained for three periods of 3 minutes each, followed by open questions and answers with instructors. Participants were strongly encouraged to ask for questions and clarifications. They were then inexperienced but well-trained traders on the simple procedures of our artificial markets. All investors can trade freely through these periods. Investors were informed that the total euro amount to be paid to them is proportional to the number of points/ECU earned in the session (following Hirota and Sunder 2007, p. 1886 and footnote n. 
8). The subjects were announced that there will be up to 30 periods, but that the session can and will be likely to end before that, at the end of whatever period. Every whole session lasted for two hours in average.

We retain two experimental treatments. The experimental design aims at studying the effect of two alternative accounting information regimes on the market pricing process. We differentiate the fair value accounting treatment, in which the payout index is linked to current market price, from the historical cost accounting treatment, in which the payout index is linked to exogenous fundamental information. In both treatments, the security pays out only one single liquidation value to its holders at the end of the last period (final payout). During the training phase, before each session, all investors were informed about the final payment linked to holding shares, and the ongoing payout index that continuously provides fundamental information about that payment on their screens. They were informed that payout index was expected to change over time during every period. No further explanation was provided about the mode of payout index change. The theoretical connection with accounting was not declared, to avoid any bias from previous knowledge and belief concerning the index.

In addition to final payments linked to holding securities, investors are allowed to exchange their securities against points, acquiring capital gains (or incurring capital losses) by trading with other investors. These additional profits (or losses) derive from ongoing payments between investors, and are different from final payments by holding securities that depend on alternative accounting regimes.

\section{Determinants of the market pricing process}

Drawing upon Smith et al (1988) and Hirota and Sunder (2007), the market pricing process is characterized here by three adjustment dynamics: the process that describes changes in the security's liquidation value; the evolution of investors' endowments and trading behavior; and the security's clearing price adjustments over time.

\subsection{Individual investors}

Each investor is endowed with 100 securities having an initial liquidation value of 100 Experimental Currency Unit (ECU or point thereafter), and 10000 points at the beginning of period 1. This implies a balanced portfolio between cash and securities worth. Huge number of shares per individual portfolio and their low face value relative to cash were intended to enhance market liquidity and encourage trading. Short selling being prohibited, investors can both buy securities if they have cash to pay for them, and/or sell any shares they have. Securities and cash are carried over from one trading period to the next. The investors' portfolio dynamics is then endogenous to the market pricing process.

During each trading period, every investor has been informed about the evolution of the market clearing price and the final payout by numerical and graphical representations. Figure in Appendix.Game captures participant's screen during the period. Together with the ongoing series of market prices and liquidation values, this screen shows the best bid and the best ask price currently available for matching; the current period number; remaining time to the end of the period; and cases (to be filled in with integer numbers) and buttons (to be pressed by mouse click) to accept or improve on outstanding proposals. Investors are also informed of their 
endowment of shares number and cash that are updated after each of their own transaction. Between two periods, investors have been informed about the over-the-period adjustments of current market price, liquidation value, their portfolio composition, and their potential income (as if the session stopped). Figure in Appendix.Game captures participant's screen during the paperwork pause. The screen shows the number of points and the number of securities (in the "endowment" window area), the market prices and the liquidation values (in the "market" window area), and the individual incomes (in the "income" area), all at the beginning and at the end of the elapsed period. In addition, Investors were provided with pens and papers to do calculations and notes, if they wish to do it.

\subsection{Share Exchange microstructure}

The trading procedure consists of continuous double auction market, implemented through the $\mathrm{z}$-Tree software (Fischbacher 2007). Investors are free to bid (proposals to sell shares) and/or ask (proposals to buy shares) for one security unit each time, by entering the wished price through their mouse and keyboard during trading periods. For sake of simplicity, they cannot enter but integer prices. They are free to accept any other trader's ask or bid, or improve on them by heightening the current ask price and lowering the current bid price by one, two, three and so on ECU/points. Agents are likewise free either to buy and/or sell whatever number of shares during the session, provided they have means to do it (no short sale or naked transaction), or to wait and do nothing.

Following Smith et al. (1988) and Hirota and Sunder (2007), price quotes must progress so as to reduce the bid-ask spread. The basic rule is that only the bighest bid to buy and the lowest offer to sell are displayed to the entire market and are open to acceptance. According to Smith and Williams (1983), this structure of the double auction market tends to better allocative efficiency by generating a competitive clearing price. Furthermore, previous price quotes that violate this rule are removed from the market book order. Agents are prevented by the price system to submit new quotes that violate this rule. The price system also checks if the agent has sufficient cash to pay for the purchase, or the share being to be sold. Once accepted by the price system, submitted quotes cannot be removed from the book order. When two quotes match, a new transaction is passed and the price system displays an updated clearing price at the transacted price. If bid and ask cross (bid is above ask), transaction is executed at the price equal to the bid or ask that came first.

\subsection{Alternative accounting regimes: the final payout structure}

We consider a security which pays only one ultimate payout $F_{T}$ at a future period $T$. Assuming no discount or interest rates, and risk-neutral assessment, the fundamental value of the security is $V_{t}=E_{t}\left(F_{T}\right)$ where $E_{t}$ is the homogeneous expectation at time $t \in[1 ; T]$. The payout index is continuously announced during each period, and changes every time that a new market clearing price is transacted. ${ }^{4}$ In historical cost accounting sessions, the payout index depends on an exogenous amount $F_{t}=F \pm \varepsilon$ where $F$ has a constant value of 100 ECU and $\varepsilon$ is a white noise

\footnotetext{
${ }^{4}$ A further experiment may analyze the market price formation when the respective timings of payout index and market price differ. Biondi, Giannoccolo and Galam (2012) provide an analytical approach taking into accounting the respective timings of individual and inter-individual decision-making, fundamental information, and the market pricing.
} 
of zero mean and unitary standard deviation. In fair value accounting sessions, the payout index depends on an endogenous amount linked to the current market price $F_{t}=p_{t} \pm \varepsilon$ where $p_{t}$ is the last market clearing price and $\varepsilon$ is a white noise of zero mean and unitary standard deviation. In both regimes, $F_{t}$ can be understood as a measure of accounting earnings, which have been accrued and shall be eventually distributed to shareholders. Both white noises capture then measurement errors and other factors affecting the working of accounting systems. Under historical cost accounting, that noise may also capture the intrinsic volatility of the security generated by the ongoing economy of the business firm. For sake of comparability, both white noises were randomly and identically generated for both kinds of treatment.

Investors were informed that every security would pay only one payout equal to the last announced value of the payout index at the end of the whole session, when $t=T$. They were not informed about the actual number of periods (15) in the session until the latter was actually terminated, but they were informed that the number can be equal or inferior than 30 , and they could have estimated that the length of time for which they had been recruited into the laboratory would end well before Period 30. This makes the final payout linked to holding shares relevant for investing and trading decision-making within every period of the whole session, or at least during the final time of each period, not only at the end of any announced last period. The payoff index becomes then the liquidation value of reference for holding shares. ${ }^{5}$

One may argue that, under fair value accounting regime, this setting is sensitive to market manipulation at the end of the period by individual strategies. One investor could purposefully offer to buy (sell) securities at increasingly higher (lower) prices at the end of the period, in order to drive the market clearing price up (down), and the strategy is self-fulfilling if other traders agree to settle those orders. Those strategies are nevertheless submitted to increasingly higher risk if some traders reverse the trend by transacting a lower (higher) price. As a matter of fact, neither clearing market series nor price orders series corroborate the existence of such strategies in any of our sessions.

\section{Economic analysis of results}

Because of the aleatory structure of the payout index, and random changes in participants, every market pricing process is somewhat unique. For sake of robustness, we have then replicated each treatment several times and assessed every result on all the periods and all the sessions by treatment (accounting design). In four sessions (numbered FV1, FV2, FV3, FV4), investors traded under the fair value accounting regime. In five sessions (numbered $\mathrm{HC} 1, \mathrm{HC} 2, \mathrm{HC} 3$, $\mathrm{HC} 4, \mathrm{HC} 5)$, investors traded under the historical cost regime. ${ }^{6}$

Figures in Appendix.DescriptiveStatistics summarize the market price series generated by all the sessions. Each figure shows the evolution of the market series and its divergence from the last

\footnotetext{
5 These liquidation values cannot be considered as the fundamental values of reference in its usual meaning. Nevertheless, they provide collective signals about the payoffs linked to holding shares, and those signals are common knowledge for all the investors.

${ }^{6}$ All results were calculated by excluding price orders and clearing prices that result from order-of-magnitude typographical errors $(69(0.28 \%)$ orders in total, on $25034(100 \%)$ orders throughout all sessions; $10(0.14 \%)$ clearing prices in total, on 7304 (100\%) prices throughout all sessions).
} 
available liquidation value, time after time, within each period and session. Tables in Appendix.DescriptiveStatistics summarize descriptive statistics of the market price series by period and session for both treatments (accounting designs). Generally speaking, independently from accounting regime, every session shows high volumes of proposals (one every second on average) and transacted prices (one every three seconds on average). Every investor passed 300 orders and settled 70 transactions, on average.

Concerning historical cost accounting, sessions $\mathrm{HC} 3$ and $\mathrm{HC} 4$ show a particularly stable market that keeps in line with the liquidation value of reference over time. Sessions HC1 and $\mathrm{HC} 2$ are relatively stable markets that remain substantially in line with liquidation values but show bubble formation both in early and late periods. Session HC5 shows a particularly stable market that peculiarly remains at a mean (median) price level of 95.45 (95), below the liquidation value of reference over time. Other sessions remarkably trade at median prices of 100 on all periods, while the mean price is above 100 in three cases (HC1: 100.34; HC2: 100.38; HC3: 100.20) and below 100 in one case (HC4: 99.84).

Concerning fair value accounting, all sessions show instable markets trading with ample fluctuations of both the market price series and its divergence from last announced liquidation values over time. Market price sequences with relative stability appear to switch toward sequences of higher volatility and divergence. In particular, session FV1 appears to trade around a central value situated around 82 points; sessions FV2 shows a remarkable downward trend over time, from 100 to 31 points; while session FV3 and FV4 largely fluctuate in both directions. For all sessions, market prices remain below the initial liquidation value of 100 points for most of the time.

We shall infer five main results from analyzing the data. These results concern the market clearing price process by technical and fundamental analysis, the formation of individual expectations, allocative efficiency, and revenue and wealth dispersion under alternative accounting regimes.

\subsection{Market clearing price process under technical analysis}

Result 1: Under historical cost accounting regime, market price series shows less price volatility and amplitude than under fair value accounting regime.

According to LeRoy (1989), economic analyses of bubbling can be distinguished between technical and fundamental analysis. Technical analysis retains measures of and controls for bubbling related to the market price series alone. By assuming "what if" the market price always equals the fundamental value of reference, they test the implied characteristics of the market price series.

We retain here some classic measures of bubbling from technical analysis, computed period by period. In particular, volatility is defined as the ratio of price standard deviation on mean price. Turnover is defined as the number of trades transacted during a period on the total share units (TSU) available on that period (9000 or 10000 according to the number of participants), or $\Sigma \mathrm{q}_{\mathrm{t}} / \mathrm{TSU}$. Normalised volatility is then the volatility for the turnover. We further introduce two measures of Price Trend Duration in both directions (downward and upward), i.e., the number of consecutive market prices that follow the same upward (downward) pattern, and a composite measure of price trend duration obtained by adding the previous two measures 
normalized for the number of trades of the period (Normalized Trend Duration).

Test results are summarized by Table in Appendix.Result1. They confirm that price bubbling measures are materially and significantly reduced (increased) by historical cost (fair value) accounting regime. In particular Mean Volatility is significantly and materially increased under fair value accounting (0.072461) than under historical cost accounting (0.0118676). Normalized Volatility is also increased (709.1495 against 116.24439). Concerning bubble duration, upward trends appear more durable under fair value accounting (duration max 1.98 and mean 0.37211, against 1.53 and 0.2489 respectively), while downward trend differences do not appear especially significant.

The influence of accounting design on bubbling is confirmed under technical analysis. Another literature strand further tests for divergences between market price and fundamental value of reference.

\subsection{Market clearing price process under fundamental analysis}

Result 2: Under historical cost accounting regime, market price shows better alignment with the liquidation value of reference than under fair value accounting regime

According to LeRoy (1989), another strand of economic analysis of bubbling relates to fundamental analysis. This literature retains measures of and controls for bubbling related to the alignment between the market clearing price series and the fundamental value series of reference. By assuming that the market price evolves over time around the fundamental value of reference, they test the implied connection between them.

In our design, fundamental values are represented by liquidation values, assuming no discount or interest rates, and investors' risk-neutrality. We retain here some classic measures of bubbling from fundamental analysis based upon the liquidation value series (F). In particular, Divergence consists of the difference between the market price and the last liquidation value $\left(\mathrm{P}_{\mathrm{t}}-\mathrm{F}_{\mathrm{t}-1}\right)$, computed time after time. Cumulated absolute divergence is the sum of the absolute values of Divergence $\Sigma\left|\mathrm{P}_{\mathrm{t}}-\mathrm{F}_{\mathrm{t}-1}\right|$, computed period by period. Price Amplitude is the difference between the maximum and the minimum of the divergence normalized by the liquidation value of reference, time after time, or $\max \left(\left(\mathrm{P}_{\mathrm{t}}-\mathrm{F}_{\mathrm{t}-1}\right) / \mathrm{F}_{\mathrm{t}-1}\right)-\min \left(\left(\mathrm{P}_{\mathrm{t}}-\mathrm{F}_{\mathrm{t}-1}\right) / \mathrm{F}_{\mathrm{t}-1}\right)$. Normalized Deviation is the turnover for the cumulated absolute divergence, or $\left(\Sigma_{\mathrm{q}_{\mathrm{t}}} / \mathrm{TSU}\right) \cdot \Sigma\left|\mathrm{P}_{\mathrm{t}}-\mathrm{F}_{\mathrm{t}-1}\right|$, period by period. Average Bias is the sum of timely divergence normalized by the liquidation value of reference, period by period, or $\Sigma\left(\left(\mathrm{P}_{\mathrm{t}}-\mathrm{F}_{\mathrm{t}-1}\right) / \mathrm{F}_{\mathrm{t}-1}\right)$. Absolute Average Bias is the sum of absolute divergence normalized by the liquidation value of reference, period by period, or $\sum\left(\left|\mathrm{P}_{\mathrm{t}}-\mathrm{F}_{\mathrm{t}-1}\right| / \mathrm{F}_{\mathrm{t}-1}\right)$.

Tables in Appendix.Result2 report all these intrinsic bubbling measures, with and without the session HC.5 that is peculiar. Our tests confirm that all intrinsic bubbling measures are materially and significantly reduced (increased) by historical cost (fair value) accounting regime. In particular, the mean divergence and the mean average bias is generally less than one point under historical cost accounting, provided that the minimum trade unit allowed to traders had been one point, while they are respectively 2.1046 and 9.310 under fair value accounting. The cumulated absolute divergence represents the market cumulative over- and underestimation relative to the ongoing fundamental value of reference, and is more than twice under fair value accounting; price amplitude is almost seven times bigger; the normalized deviation is at least the 
double; the average bias is nine times bigger; and the absolute average bias is four time bigger.

As a matter of fact, under historical cost accounting, only one session shows significant but not material divergence between market price and fundamental value of reference. This is why we have analyzed all measures with and without that session. In fact, the disconnection may be explained by a sort of behavioral financial safety margin that became consensual among investors trading on that market. Even though investors collectively renounced to potential capital gains as computed on ongoing liquidation values, they successfully prevented potential capital losses by trading just under the frontier generated by the minimum threshold level of the fundamental value series. This result is also in line with discounted fundamental value as computed by riskadverse investors, according to Smith et al. (1988, p. 1144): the present value of future payouts less a constant. In our case, this implies a discounted fundamental value of $(97.083 \pm 0.058)=$ $100-2.917$, including a $2.9 \%$ discount. $^{7}$ This value remains then within the range of experienced minimum liquidation values of reference, which, by construction, add a white noise with null mean and unitary standard deviation.

The influence of accounting design on bubbling is confirmed under fundamental analysis. Features of the market pricing process further relate to the formation of individual expectations and bidding/asking strategies.

\subsection{Individual expectations and bidding/asking strategies}

Result 3: Under historical cost accounting regime, individual price expectations are consistent with backward induction; under fair value accounting regime, they are consistent with forward induction.

Artificial security markets enable to control the whole market environment, and the analysis of individual expectations is then greatly facilitated. In fact, our analysis focalizes on coordination issue and the response to this issue that is provided by collective devices generating payouts and information thereof, i.e., the accounting systems. Nevertheless, we run simple linear regression analysis to assess the impact of featuring factors that are assumed to shape the formation of the market clearing price over time.

In particular, we analyze the market price formation process using two backward induction factors and two forward induction factors. From the backward induction side, the heuristic model assumes that investors collectively generate the current price $\left(\mathrm{P}_{t}\right)$ by inducting from the ongoing liquidation values of reference $\left(\mathrm{F}_{\mathrm{t}-1}\right)$. The divergence of the price from the past liquidation value $\left(\mathrm{P}_{\mathrm{t}}-\mathrm{F}_{\mathrm{t}-1}\right)$ and the intrinsic variation of the latter $\left(\mathrm{F}_{\mathrm{t}}-\mathrm{F}_{\mathrm{t}-1}\right)$ are then expected to become relevant to investing and trading decision-making. From the forward induction side, the heuristic model assumes that investors collectively generate the current price $\left(\mathrm{P}_{\mathrm{t}}\right)$ by extrapolating from the market price trend $\left(\mathrm{P}_{\mathrm{t}}-\mathrm{P}_{\mathrm{t}-1}\right)$ and "revealed excess demand arising from capital gains expectations" $\left(\mathrm{B}_{\mathrm{t}-1}-\mathrm{A}_{\mathrm{t}-1}\right)$, the latter factor being defined as the difference between the best bid price and the best ask price before the trade (comp. Smith et al. 1988, p. 1141). The combined linear regression model is defined as follows, time after time:

7 This coefficient was estimated by the combined linear regression model discussed below. Its $t$ test was 1663 , significant at $<1 \%$. 


$$
P_{t}=c+a_{1}\left(P_{t}-P_{t-1}\right)+a_{2}\left(B_{t-1}-A_{t-1}\right)+a_{3}\left(F_{t}-F_{t-1}\right)+a_{4}\left(P_{t}-F_{t-1}\right)
$$

Where $\mathrm{P}_{\mathrm{i}}$ is the market clearing price at time $i ; \mathrm{F}_{\mathrm{i}}$ is the liquidation value of reference at time $i ; \mathrm{B}_{\mathrm{i}}$ is the best bid price at time $i$; and $\mathrm{A}_{\mathrm{i}}$ is the best ask price at time $i$. The combined model allows for the possibility that investors use some combinations of the four simple factors to form their expectations. It also helps to detect any biases due to the omitted variables problem. We estimate regressions on two samples, one had pooled data from all the four fair value accounting sessions, and the other has pooled the data from all the five historical cost accounting sessions. Furthermore, we repeat regressions on each session by distinguishing between fair value and historical cost treatment. Our null hypothesis is that expectations are static, $\mathrm{E}_{\mathrm{t}}\left(\mathrm{P}_{\mathrm{t}+1}\right)=\mathrm{P}_{\mathrm{t}}+\varepsilon$, implying that all the four parameters $a$ are expected to be zero.

Tables in Appendix.Result3 show results from pooled regressions (session regressions are omitted). ${ }^{8}$ Under fair value accounting regime, both forward induction factors are significantly correlated to the clearing market price. Market price trend has a positive coefficient as expected, and so does bid-ask spread before trade that appears to have a negative coefficient. ${ }^{9}$ Our estimations indicate that the market price trend factor has a considerable effect on market clearing price: its rise of 1 point raising the market price by 0.7 points, according to its linear regression non-standardized coefficient. On the contrary, no backward induction factors are significant, neither the liquidation value trend or the market price divergence. In this environment, market price levels and paths become erratic and lose earnings anchor; investors tend to form their expectations of future prices by forward, not backward, induction. Accounting plays its role from the market, and loses its relevance in financial decision-making. Under historical cost accounting regime, both backward induction factors are significantly correlated to the market clearing price. Interestingly, the liquidation value trend has a negative coefficient, while the divergence has a positive one. ${ }^{10,11}$ Furthermore, even one forward induction factor, the market price trend, has a small and significantly positive coefficient. These results suggest that the liquidation value not only determines transaction prices under historical cost accounting, but also critically affects the price expectations. Whenever market prices tend to increase when the

\footnotetext{
${ }^{8}$ Under fair value accounting, linear regression coefficients by session were significant and positive for Market Price Trend in FV1 and FV3; significant and positive in FV1, while significant and negative in FV4 for Bid-Ask Spread Before Trade; never significant for Liquidation Value Trend and Divergence or elsewhere. Under historical cost accounting, linear regression coefficients by session were significant and positive for Market Price Trend in all sessions; significant and negative in $\mathrm{HC} 1$ and $\mathrm{HC} 3$, significant and positive in $\mathrm{HC} 2$ and $\mathrm{HC} 5$, and not significant in HC4 for Bid-Ask Spread Before Trade; significant and negative for Liquidation Value Trend in all sessions; significant and positive for Divergence in all sessions.

${ }_{9}$ According to Smith et al. (1988, p. 1141), "excess demand is positively correlated to excess bids (numbers of bids entered minus number of offers) in those markets which spontaneously self-generate an expectation of capital gains (losses)." Here, we utilize the bid-ask spread that reverses the correlation (bid meaning "offer" while ask meaning "bid").

${ }^{10}$ Hirota and Sunder (2007, p. 1899) also estimated a significantly and materially positive coefficient for $D_{\max }-P_{t}$, in long-horizon sessions, corresponding here to the reverse of the divergence factor $\left(\mathrm{P}_{t}-\mathrm{F}_{\mathrm{t}-1}\right)$ in historical cost accounting sessions. Liquidation value trend did not apply to their design.

11 This correlation is made even more remarkable by noticing that trade proposals where limited at integer prices, while the liquidation values evolved on a continuous range. The fine tuning was then reduced by trading constraints. Under historical cost accounting, $46.8 \%$ of liquidation values were actually at less than one point of distance from the central value of 100 .
} 
divergence increases, their limited price trend behavior is overcompensated by the evolution of the liquidation value that plays a decisive role as an accounting lighthouse. When the market price goes too far from fundamentals, it eventually reverses on them, generating the significantly and materially negative correlation with the liquidation value trend. In this environment, speculative trades by fundamentalist strategies (which trade on the basis of fundamentals) lead the market to keep in line with fundamentals by dominating speculative trades by chartist strategies (which trade on the basis of market price trend and other market conditions) that would tend to divert it from them. These findings are also consistent with Hommes et al. (2005) showing that individual forecasting may coordinate on trend following strategies, causing security prices to fluctuate and deviate from their fundamentals.

On this basis, to refine our regression analysis, we add a further factor to the previous model to take into account the forecasting error correction ERRt defined by Biondi, Giannoccolo and Galam (2012) as follows:

$$
E R R_{t}=\sum_{n=1}^{N}(-\beta)^{n}\left(P_{t-n}-P_{t-n+1}+m\left(P_{t-n}-P_{t-n-1}\right)\right)+1 / 2 \sum_{n=1}^{N}(-\beta)^{n}\left(\gamma \cdot F_{t-n}\right)
$$

Where, for sake of simplicity, $\beta=0.5, m=0.5, \gamma=1$, and $N=5$, assuming a uniform population with the same weights for forecasting error correction, fundamentalist and chartist strategies over time and individuals, as well as a truncated past memory of 5 periods. Table in Appendix.Result 3 summarizes the further estimations. They confirm all the correlations and their signs already estimated, and enhance previous results by making the market price trend insignificant under historical cost accounting regime. Further specifications of the model including lagged factors and non-linear relationships may further investigate these insights, including dynamic estimation fitting of the forecasting error correction factor.

Moreover, the working of the market pricing process has important consequences for its allocative efficiency, that is, its capacity to generate a "fair" price from the viewpoint of resource allocation over time and among investors.

\subsection{Allocative efficiency}

Result 4: Market exchange appears to show better allocative efficiency under historical cost accounting design when all transactions are taken into account. This effect disappears when only transactions traded at a large distance from liquidation values are considered.

According to Hirota and Sunder (2007, p. 1900, footnote 19), when all investors had the same dividend, allocative efficiency is undefined. We try here to measure it on the basis of the quota of securities transferred near to their "fundamental values" of reference, which are ongoing liquidation values in our setting. When securities are traded far from these values, investors increasingly confront with transacted prices that diverge from the expected liquidation value of that security, i.e., from its intrinsic value at that point of time. Since every trader would eventually get the same liquidation payout from holding the security, the market is expected to exert pressure to make the allocation of resources more efficient by reducing the distance between price and that ultimate payout (comp. Hirota and Sunder 2007, p. 1909).

We identify all the shares transferred at $5 \%$ and $10 \%$ above the intrinsic value of reference 
at the time of the transaction. This implies that the absolute value of Price Amplitude defined as $\left(\mathrm{P}_{\mathrm{t}+1}-\mathrm{F}_{\mathrm{t}}\right) / \mathrm{F}_{\mathrm{t}}$ is more than $0.05(5 \%)$ and $0.1(10 \%)$ for that transaction. For all these transactions, we compute the cumulated number and cumulated relative value defined as $\sum\left|\mathrm{P}_{\mathrm{t}}-\mathrm{F}_{\mathrm{t}-1} / \mathrm{F}_{\mathrm{t}-1}\right|$, period by period. Table in Appendix. Result 4 reports descriptive statistics and tests for these measures. Results do not corroborate that allocative efficiency is improved (worsened) by historical cost (fair value) accounting regime. Most significance tests failed, and the differences are not material. However, these results might depend on the structure of liquidation values that, under fair value accounting, follow the market prices time after time. Furthermore, these results might depend on the peculiar measures of market inefficiency defined above for the test. Instead, we can have recourse to some measures already utilized to assess fundamental bubbling. In particular, the Absolute Average Bias is defined as $\sum\left(\left|\mathrm{P}_{\mathrm{t}+1}-\mathrm{F}_{\mathrm{t}}\right| / \mathrm{F}_{\mathrm{t}}\right)$ for all transactions within a period: its mean (median) was 19.477 (12.262) under fair value accounting, while it was 4.8648 (3.27515) under historical cost accounting, that means a material and significant inefficiency when all transactions are taken into account. The same is true for Cumulative Absolute Divergence defined as $\sum\left|\mathrm{P}_{\mathrm{t}+1}-\mathrm{F}_{\mathrm{t}}\right|$ for all transactions within a period: its mean (median) is 1201.09986 (935.837) under fair value accounting, while it is 486.7235 (326.54388) under historical cost accounting. The latter result is even more important provided that the market price levels remained systematically lower in fair value sessions than in historical cost sessions. In fact, further specific tests are required to comfort our preliminary results on allocative efficiency and accounting design.

Moreover, bubbles may also have significant distributive effects in the form of increasing the dispersion of revenue and wealth among investors.

\subsection{Revenue and wealth dispersion}

Result 5: Historical cost accounting regime reduces inter-individual dispersion of investor revenue and wealth relative to fair value accounting regime

We analyze two classic measures of revenue and wealth dispersion, the Gini and Teil Indexes, by period and by session. For every period, end-of-period individual profits are computed by adding held cash to the current liquidation value of all held shares.

The Gini Index $\left(\mathrm{G}_{t}\right)$ at the end of each period is computed on the non-decreasing ranking of individual profits $\left(y_{i}<y_{i+1}\right)$ as follows:

$$
G_{t}=\frac{2 \sum_{i=1}^{n} i \cdot y_{i}}{n \sum_{i=1}^{n} y_{i}}-\frac{n+1}{n} \text { where } n \text { is the number of individuals ( } 9 \text { or } 10 \text { in ours samples) }
$$

More the wealth distribution is uniform, more the Gini Index approaches to zero. More the wealth distribution is concentrated in few hands, more the Gini Index approaches 0,889 for a sample of 9 participants, or 0.9 for a sample of 10 participants.

The Theil index is computed at the end of each period on the basis of relative profits of individual investors. Relative profits consist of the end-of-period trader's profit in points $\left(x_{i}\right)$ 
normalized by the average profit on all traders $(\bar{x})$ in the same period.

$$
T_{t}=\frac{\sum_{i=1}^{n}\left(\frac{x_{i}}{\bar{x}} \cdot \ln \frac{x_{i}}{\bar{x}}\right)}{n \cdot \ln (n)} \text { where } n \text { is the number of individuals }
$$

More relative profits are equal, more the Theil index is near to zero. More relative profits are concentrated, more the Theil index approaches to one.

Tables and Figures in Appendix.Result5 show significant and material differences between alternative accounting regimes. The mean (median) Gini Index under fair value accounting is $0.0288222(0.0119574)$, while it is $0.0029952(0.0021996)$ under historical cost accounting. The mean (median) Theil Index under fair value accounting is 0.019956755 (0.0000247), while it is $0.0010712(0.0000068)$ under historical cost accounting. Both indexes corroborate that interindividual dispersion of revenue/wealth is less under historical cost accounting than under fair value accounting regime, with several statistical difference tests significant at $<0.2 \%$ or less.

\section{Conclusion}

In nine artificial spot security markets, we observe that, when investors trade under fair value accounting regime, the market price tends to deviate from fundamentals to form bubbles. In these circumstances, prices lose their anchors on earnings and are more volatile. The allocation of resources becomes less efficient and wealth distribution more skewed. On the contrary, under historical cost accounting regime, the market price tends to align with fundamentals and the occurrence, duration and materiality of bubbling is reduced. Market prices remain connected to earnings and are less volatile. The allocation of resources is more efficient and wealth distribution less skewed. These results are robust to several replications of both alternative experimental treatments under analogous conditions with different subjects.

These findings show how the institutional architecture enabling trade actively frames and shapes the formation of market clearing prices over time, particularly the accounting regime that provides collective signals of accrued earnings (and eventual dividend payouts) to shareholders. Together with individual expectations and the market microstructure (the price system), the accounting system contributes then to the working of the share Exchange. In particular, accounting information and its overarching structure are important to prevent market exuberance, excess volatility and the formation of financial bubbles. They further have relevant effects on market allocative efficiency, and revenue and wealth distribution among investors.

\section{REFERENCES}

Abreu, D., AND M. K. Brunnermeier. 2003. Bubbles and crashes. Econometrica 71 (1): 173-204.

Anthony, R. N. 2004. Rethinking the rules of financial accounting. Examining the rules for proper reporting. New York: McGraw-Hill.

AzARIADIS, C. 1981. Self-fulfilling prophecies. Journal of Economic Theory 25 (3): 380-396.

Ball, S. B., AND C. A. Holt. 1998. Speculation and bubbles in an asset market. Journal of Economic 
Perspectives 12 (1): 207-218.

Biondi, Y. 2011. The pure logic of accounting: A critique of the Fair Value Revolution. Accounting, Economics, and Law: A Convivium 1 (1).

Biondi, Y., P. Giannoccolo, and S. Galam. 2012. The formation of share market prices under heterogeneous beliefs and common knowledge. Physica A 391 (22): 5532-5545.

Brunnermeier, M. K. 2001. Asset pricing under asymmetric information: Bubbles, crashes, technical analysis and herding. Oxford: Oxford University Press.

Camerer, C. 1989. Bubbles and fads in asset prices. Journal of Economic Surveys 3 (1): 3-41.

Davis, D. D., And C. A. Holt. 1993. Experimental Economics. Princeton: Princeton University Press.

Fischbacher, U. 2007. z-Tree: Zurich Toolbox for ready-made economic experiments. Experimental Economics 10 (2): 171-178.

FRYDMAN, R. 1982. Towards an understanding of market processes: Individual expectations, learning, and convergence to rational expectations equilibrium. American Economic Review 72 (4): 652-668.

Holt, C. A. 1995. Industrial organization: A survey of laboratory research. KageL, J. H., AND A. E. Roth eds. Handbook of Experimental Economics. Princeton, New Jersey: Princeton University Press: 349443.

Laffont, J. -J, and J. Tirole. 1993. A Theory of Incentives in Regulation and Procurement. Cambridge, MA: MIT Press.

Hommes, C. H., J. Sonnemans, J. Tuinstra, and H. van de Velden. 2005. Coordination of expectations in asset pricing experiments. Review of Financial Studies 18 (3): 955-980.

KiRChLER, M. 2009. Underreaction to fundamental information and asymmetry in mispricing between bullish and bearish markets. An experimental study, Journal of Economic Dynamics and Control 33 (2): 491-506.

LERoy, S. 1989. Efficient capital markets and martingales. Journal of Economic Literature 27 (4): 15831621.

LinTNER, J. 1956. Distribution of incomes of corporations among dividends, retained earnings and taxes. American Economic Review, Papers and Proceedings 46 (2): 97-113.

Malkiel, B. 2003. The efficient market hypothesis and its critics. Journal of Economic Perspectives 17 (1): 59-82.

Penman, S. 2011. Accounting for Value. New York: Columbia Business School Publishing.

PlotT, C. 1989. An updated review of industrial organization: Applications of experimental methods. Schmalensee, R., AND R. Willig eds. Handbook of Industrial Organization. North-Holland, Amsterdam.

SHubiK, M. 1993. Accounting and its relationship to general equilibrium theory. Reprinted. KiRAT, T., Y. BIONDI, AND A. CANZIANI eds. 2007. The Firm as an Entity: Implications for Economics, Accounting, and Law. New York and London: Routledge: 73-81.

Smith, V. L., AND A. W. Williams. 1983. An experimental comparison of alternative rules for competitive market exchange. Engelbrecht-Wiggans, R., M. Shubik, and R. StarR eds. Auctions, Bidding and Contracting: Uses and Theory. New York: New York University Press.

Smith, V. L., G. L. Suchanek, and A. W. Williams. 1988. Bubbles, crashes, and endogenous expectations in experimental spot asset markets. Econometrica 56 (5): 1119-1151.

Smith, V. L., M. van Boening, and C. P. Wellford. 2000. Dividend timing and behavior in laboratory asset markets. Economic Theory 16 (3): 567-583.

Stiglitz, J. E. 1990. Symposium on bubbles. Journal of Economic Perspectives. 4 (2): 13-18.

Sunder, S. 1995. Experimental asset markets: A survey. Roth, A. AND J. Kagel eds. Handbook of Experimental Economics. Princeton: Princeton University Press: 445-500.

Sunder, S. 2002. Knowing what others know: common knowledge, accounting, and capital markets. Accounting Horizons 16 (4): 305-318. 
An Experimental Analysis of Artificial Spot Security Markets

\section{Appendix.Descriptive Statistics.Table: Market Price Series by Session}

Fair Value Accounting

\begin{tabular}{|c|c|c|c|c|c|c|c|c|c|c|}
\hline Session & Period & $\mathrm{N}$ & Mean & $\begin{array}{c}\text { Std. } \\
\text { Deviation }\end{array}$ & $\begin{array}{l}\text { Std. Error } \\
\text { of Mean }\end{array}$ & Median & Minimum & Maximum & Kurtosis & Skewness \\
\hline \multirow{16}{*}{ FV1 } & 1 & 55 & 82,47 & 7,037 & ,949 & 82,00 & 55 & 95 & 4,534 & $-1,468$ \\
\hline & 2 & 44 & 82,45 & 4,603 & 694 & 83,00 & 60 & 94 & 13,313 & $-2,294$ \\
\hline & 3 & 70 & 75,31 & 5,607 & 670 & 75,00 & 63 & 86 & $-1,113$ &,- 040 \\
\hline & 4 & 54 & 80,06 & 3,993 & ,543 & 80,00 & 75 & 89 &,- 893 & ,251 \\
\hline & 5 & 60 & 81,80 & 2,887 & 373 & 81,00 & 78 & 90 & 1,842 & 1,331 \\
\hline & 6 & 63 & 81,63 & 5,968 & ,752 & 82,00 & 59 & 90 & 7,695 & $-2,385$ \\
\hline & 7 & 49 & 82,43 & 3,725 & ,532 & 82,00 & 69 & 90 & 4,631 & $-1,437$ \\
\hline & 8 & 62 & 81,48 & 3,836 & ,487 & 83,00 & 73 & 87 &,- 180 &,- 930 \\
\hline & 9 & 82 & 82,65 & 3,415 & ,377 & 82,50 & 70 & 91 & 3,044 &,- 523 \\
\hline & 10 & 71 & 83,89 & 3,491 & ,414 & 84,00 & 70 & 98 & 6,440 &,- 011 \\
\hline & 11 & 70 & 82,11 & 3,365 & ,402 & 82,00 & 75 & 92 & 1,688 & 1,031 \\
\hline & 12 & 83 & 80,42 & 9,929 & 1,090 & 83,00 & 49 & 90 & 5,261 & $-2,422$ \\
\hline & 13 & 76 & 82,20 & 6,075 & ,697 & 84,00 & 65 & 90 & 3,605 & $-1,975$ \\
\hline & 14 & 53 & 79,51 & 6,591 & ,905 & 80,00 & 60 & 95 & 4,310 & $-1,661$ \\
\hline & 15 & 73 & 78,89 & 4,517 &, 529 & 80,00 & 70 & 90 & ,844 &, 527 \\
\hline & Total & 965 & 81,12 & 5,779 & ,186 & 82,00 & 49 & 98 & 7,322 & $-1,924$ \\
\hline \multirow[t]{16}{*}{ FV2 } & 1 & 92 & 79,80 & ,940 & ,098 & 80,00 & 75 & 80 & 21,816 & $-4,782$ \\
\hline & 2 & 99 & 80,03 & 5,530 &, 556 & 80,00 & 45 & 100 & 27,507 & $-3,323$ \\
\hline & 3 & 42 & 73,86 & 3,646 &, 563 & 75,00 & 70 & 80 & $-1,427$ & ,168 \\
\hline & 4 & 47 & 75,81 & 1,262 & ,184 & 76,00 & 74 & 79 & 1,184 & ,987 \\
\hline & 5 & 28 & 72,57 & 1,574 & ,297 & 72,50 & 70 & 75 &,- 730 &,- 264 \\
\hline & 6 & 75 & 57,31 & 8,539 & ,986 & 50,00 & 50 & 73 & $-1,191$ & 641 \\
\hline & 7 & 71 & 42,73 & 11,581 & 1,374 & 48,00 & 28 & 70 &,- 985 & 132 \\
\hline & 8 & 68 & 39,69 & 4,012 & ,487 & 40,00 & 35 & 60 & 8,962 & 1,933 \\
\hline & 9 & 74 & 48,42 & 2,393 & ,278 & 49,00 & 45 & 55 &,- 108 & ,017 \\
\hline & 10 & 71 & 46,13 & 1,511 & 179 & 46,00 & 44 & 50 & $-1,038$ & ,264 \\
\hline & 11 & 53 & 41,34 & 1,285 & ,177 & 42,00 & 40 & 45 &, 721 & ,795 \\
\hline & 12 & 87 & 39,84 & ,400 & 043 & 40,00 & 39 & 41 & 1,430 & $-1,304$ \\
\hline & 13 & 46 & 39,17 & 3,261 & ,481 & 40,00 & 35 & 45 & $-1,553$ &,- 134 \\
\hline & 14 & 38 & 37,32 & ,873 & 142 & 38,00 & 35 & 38 & ,788 & $-1,197$ \\
\hline & 15 & 46 & 31,59 & 1,857 & ,274 & 31,00 & 29 & 35 &,- 253 & 1,032 \\
\hline & Total & 937 & 54,62 & 17,835 & ,583 & 48,00 & 28 & 100 & $-1,408$ &, 404 \\
\hline FV3 & 1 & 32 & 94,31 & 4,659 & ,824 & 95,00 & 83 & 105 & 1,216 &,- 452 \\
\hline
\end{tabular}


(-Continued)

\begin{tabular}{|c|c|c|c|c|c|c|c|c|c|c|}
\hline Session & Period & $\mathrm{N}$ & Mean & $\begin{array}{c}\text { Std. } \\
\text { Deviation }\end{array}$ & $\begin{array}{l}\text { Std. Error } \\
\text { of Mean }\end{array}$ & Median & Minimum & Maximum & Kurtosis & Skewness \\
\hline & 2 & 39 & 92,64 & 1,885 & ,302 & 93,00 & 89 & 96 &,- 718 &,- 119 \\
\hline & 3 & 43 & 89,98 & 5,436 & ,829 & 92,00 & 75 & 105 & 3,916 & $-1,358$ \\
\hline & 4 & 44 & 91,70 & 3,461 & ,522 & 91,00 & 80 & 102 & 4,633 & ,272 \\
\hline & 5 & 32 & 91,16 & 3,620 & 640 & 91,50 & 79 & 105 & 10,113 & 601 \\
\hline & 6 & 31 & 91,26 & 1,316 & ,236 & 91,00 & 88 & 94 & ,272 &,- 418 \\
\hline & 7 & 44 & 94,95 & 2,869 & ,432 & 95,00 & 88 & 105 & 2,525 & 815 \\
\hline & 8 & 31 & 96,81 & 1,302 & ,234 & 96,00 & 95 & 100 &,- 316 &, 577 \\
\hline & 9 & 39 & 94,21 & 3,155 & ,505 & 94,00 & 88 & 105 & 2,582 & 1,210 \\
\hline & 10 & 26 & 93,50 & 2,387 & ,468 & 94,50 & 88 & 97 &,- 156 &,- 917 \\
\hline & 11 & 28 & 94,86 & 7,639 & 1,444 & 95,00 & 78 & 125 & 9,844 & 1,677 \\
\hline & 12 & 40 & 90,30 & 12,904 & 2,040 & 92,00 & 70 & 122 & ,916 & 695 \\
\hline & 13 & 49 & 82,16 & 14,668 & 2,095 & 79,00 & 64 & 125 & ,254 & ,718 \\
\hline & 14 & 39 & 81,33 & 5,303 & ,849 & 80,00 & 71 & 95 & 1,498 & 1,321 \\
\hline & 15 & 39 & 91,03 & 3,407 &, 545 & 91,00 & 79 & 99 & 4,590 &,- 145 \\
\hline & Total & 556 & 90,97 & 7,894 & ,335 & 92,00 & 64 & 125 & 3,926 &,- 588 \\
\hline \multirow[t]{16}{*}{ FV4 } & 1 & 47 & 78,89 & 5,865 & ,856 & 80,00 & 60 & 90 & 2,044 &,- 655 \\
\hline & 2 & 36 & 66,86 & 6,630 & 1,105 & 70,00 & 54 & 80 &,- 104 &,- 865 \\
\hline & 3 & 30 & 66,80 & 4,350 & ,794 & 68,50 & 60 & 80 & 1,391 & ,530 \\
\hline & 4 & 33 & 65,61 & 4,769 & 830 & 65,00 & 55 & 75 & ,629 & 822 \\
\hline & 5 & 33 & 61,79 & 1,816 & ,316 & 62,00 & 60 & 65 &,- 609 & ,803 \\
\hline & 6 & 25 & 63,68 & 2,462 & ,492 & 65,00 & 60 & 68 & $-1,117$ &,- 327 \\
\hline & 7 & 22 & 62,32 & 4,052 & ,864 & 61,50 & 55 & 70 &,- 961 &,- 004 \\
\hline & 8 & 39 & 73,87 & 7,374 & 1,181 & 74,00 & 50 & 100 & 5,796 & ,334 \\
\hline & 9 & 36 & 75,14 & 11,462 & 1,910 & 74,00 & 55 & 120 & 6,526 & 2,131 \\
\hline & 10 & 29 & 87,79 & 18,074 & 3,356 & 86,00 & 45 & 150 & 4,739 & 862 \\
\hline & 11 & 44 & 89,73 & 9,524 & 1,436 & 89,00 & 74 & 120 & 3,162 & 1,297 \\
\hline & 12 & 35 & 90,54 & 8,756 & 1,480 & 88,00 & 82 & 120 & 5,952 & 2,275 \\
\hline & 13 & 30 & 86,03 & 6,105 & 1,115 & 85,00 & 76 & 98 &,- 807 & 204 \\
\hline & 14 & 41 & 78,80 & 18,472 & 2,885 & 85,00 & 30 & 100 &,- 224 &,- 951 \\
\hline & 15 & 40 & 78,62 & 15,845 & 2,505 & 82,50 & 40 & 100 &,- 663 &,- 588 \\
\hline & Total & 520 & 75,95 & 13,844 & 607 & 75,00 & 30 & 150 & 1,334 &, 550 \\
\hline
\end{tabular}


Bensimbon and Biondi: Financial Bubbles, Common Knowledge and Alternative Accounting Regimes: An Experimental Analysis of Artificial Spot Security Markets

Historical Cost Accounting

\begin{tabular}{|c|c|c|c|c|c|c|c|c|c|c|}
\hline Session & Period & $\mathrm{N}$ & Mean & $\begin{array}{c}\text { Std. } \\
\text { Deviation }\end{array}$ & $\begin{array}{l}\text { Std. Error } \\
\text { of Mean }\end{array}$ & Median & Minimum & Maximum & Kurtosis & Skewness \\
\hline \multirow[t]{16}{*}{$\mathrm{HC} 1$} & 1 & 19 & 99,53 & 1,020 & ,234 & 100,00 & 98 & 102 & ,674 & ,447 \\
\hline & 2 & 25 & 97,84 & 4,375 & ,875 & 99,00 & 80 & 101 & 12,054 & $-3,332$ \\
\hline & 3 & 28 & 95,54 & 5,706 & 1,078 & 98,00 & 80 & 101 & 2,498 & $-1,757$ \\
\hline & 4 & 16 & 98,50 & 1,506 & ,376 & 99,00 & 95 & 100 & 2,419 & $-1,674$ \\
\hline & 5 & 36 & 98,92 & 1,763 & ,294 & 99,00 & 90 & 101 & 19,247 & $-3,876$ \\
\hline & 6 & 33 & 98,94 & ,933 & ,162 & 99,00 & 97 & 100 & $-1,382$ &,- 120 \\
\hline & 7 & 30 & 99,37 & 1,066 & ,195 & 100,00 & 95 & 100 & 9,041 & $-2,644$ \\
\hline & 8 & 35 & 99,37 & ,731 & ,124 & 99,00 & 97 & 100 & 1,832 & $-1,201$ \\
\hline & 9 & 50 & 100,96 & 2,128 & ,301 & 100,00 & 98 & 106 &,- 217 & ,862 \\
\hline & 10 & 77 & 100,36 & 2,772 & ,316 & 100,00 & 90 & 103 & 8,215 & $-2,646$ \\
\hline & 11 & 66 & 100,00 & ,877 & ,108 & 100,00 & 99 & 102 & $-1,376$ & 141 \\
\hline & 12 & 123 & 100,14 & 693 & ,063 & 100,00 & 99 & 104 & 9,072 & 2,359 \\
\hline & 13 & 108 & 100,00 & 1,260 & ,121 & 100,00 & 98 & 105 & 6,179 & 1,969 \\
\hline & 14 & 102 & 102,93 & 4,442 & ,440 & 100,00 & 99 & 115 & ,817 & 1,389 \\
\hline & 15 & 77 & 102,79 & 3,511 & ,400 & 102,00 & 98 & 110 &,- 017 & ,996 \\
\hline & Total & 825 & 100,34 & 3,087 & 107 & 100,00 & 80 & 115 & 12,304 & ,055 \\
\hline \multirow[t]{16}{*}{$\mathrm{HC} 2$} & 1 & 29 & 99,66 & 1,045 & 194 & 100,00 & 97 & 102 & ,595 &,- 041 \\
\hline & 2 & 34 & 99,88 & 7,117 & 1,221 & 100,00 & 65 & 120 & 20,011 & $-3,053$ \\
\hline & 3 & 42 & 99,69 & 1,297 & ,200 & 99,50 & 98 & 103 & 1,254 & 1,107 \\
\hline & 4 & 28 & 100,14 & 651 & ,123 & 100,00 & 99 & 101 &,- 486 &,- 142 \\
\hline & 5 & 64 & 101,03 & 3,122 & ,390 & 101,00 & 80 & 104 & 33,039 & $-4,845$ \\
\hline & 6 & 39 & 100,38 & ,544 & ,087 & 100,00 & 99 & 101 &,- 976 &,- 031 \\
\hline & 7 & 53 & 100,53 &, 504 & ,069 & 101,00 & 100 & 101 & $-2,066$ &,- 117 \\
\hline & 8 & 45 & 100,69 & ,468 & ,070 & 101,00 & 100 & 101 & $-1,349$ &,- 844 \\
\hline & 9 & 48 & 100,42 & ,498 & ,072 & 100,00 & 100 & 101 & $-1,962$ & ,349 \\
\hline & 10 & 61 & 100,51 &, 536 & ,069 & 100,00 & 100 & 102 & $-1,213$ & ,302 \\
\hline & 11 & 62 & 100,44 & ,532 & ,068 & 100,00 & 99 & 101 & $-1,280$ &,- 073 \\
\hline & 12 & 53 & 100,55 & ,539 & ,074 & 101,00 & 99 & 101 &,- 897 &,- 576 \\
\hline & 13 & 52 & 100,40 & ,495 & ,069 & 100,00 & 100 & 101 & $-1,912$ & ,404 \\
\hline & 14 & 63 & 100,30 &, 557 & ,070 & 100,00 & 99 & 101 &,- 546 &,- 016 \\
\hline & 15 & 32 & 100,16 & ,369 & ,065 & 100,00 & 100 & 101 & 2,078 & 1,988 \\
\hline & Total & 705 & 100,38 & 1,926 & ,073 & 100,00 & 65 & 120 & 194,058 & $-8,896$ \\
\hline \multirow[t]{4}{*}{$\mathrm{HC} 3$} & 1 & 41 & 98,34 & 7,806 & 1,219 & 100,00 & 50 & 101 & 39,495 & $-6,235$ \\
\hline & 2 & 53 & 100,38 & 1,147 & ,158 & 100,00 & 98 & 103 & ,203 & ,392 \\
\hline & 3 & 67 & 99,58 & ,838 & ,102 & 100,00 & 98 & 103 & 6,773 & 1,886 \\
\hline & 4 & 75 & 99,52 & ,665 & ,077 & 99,00 & 99 & 101 &,- 273 & ,917 \\
\hline
\end{tabular}


(-Continued)

\begin{tabular}{|c|c|c|c|c|c|c|c|c|c|c|}
\hline Session & Period & $\mathrm{N}$ & Mean & $\begin{array}{c}\text { Std. } \\
\text { Deviation }\end{array}$ & $\begin{array}{l}\text { Std. Error } \\
\text { of Mean }\end{array}$ & Median & Minimum & Maximum & Kurtosis & Skewness \\
\hline & 5 & 73 & 100,07 & ,304 & ,036 & 100,00 & 99 & 101 & 7,151 & 1,833 \\
\hline & 6 & 73 & 100,58 & 2,351 & ,275 & 100,00 & 100 & 120 & 67,268 & 8,050 \\
\hline & 7 & 70 & 100,30 & ,598 & ,072 & 100,00 & 99 & 101 &,- 564 &,- 217 \\
\hline & 8 & 58 & 100,26 & ,849 & 112 & 100,00 & 95 & 101 & 25,708 & $-4,090$ \\
\hline & 9 & 52 & 100,67 &, 550 & ,076 & 101,00 & 100 & 102 &,- 670 &,- 005 \\
\hline & 10 & 81 & 101,01 &, 536 & ,060 & 101,00 & 100 & 102 & ,633 & ,012 \\
\hline & 11 & 59 & 100,44 & ,623 & ,081 & 101,00 & 99 & 101 &,- 489 &,- 652 \\
\hline & 12 & 82 & 100,45 & 1,135 & ,125 & 101,00 & 95 & 102 & 11,584 & $-2,682$ \\
\hline & 13 & 94 & 100,22 & ,805 & ,083 & 100,00 & 99 & 102 & $-1,146$ &,- 304 \\
\hline & 14 & 89 & 100,38 & ,791 & ,084 & 101,00 & 99 & 101 &,- 929 &,- 800 \\
\hline & 15 & 46 & 100,02 &, 537 & ,079 & 100,00 & 99 & 102 & 4,247 & ,923 \\
\hline & Total & 1013 & 100,20 & 1,897 &, 060 & 100,00 & 50 & 120 & 496,476 & $-17,287$ \\
\hline \multirow[t]{16}{*}{$\mathrm{HC} 4$} & 1 & 87 & 100,33 & ,831 & ,089 & 100,00 & 99 & 102 &,- 040 & ,674 \\
\hline & 2 & 53 & 99,70 & ,638 & ,088 & 100,00 & 99 & 101 &,- 632 & ,356 \\
\hline & 3 & 58 & 99,79 & ,450 & ,059 & 100,00 & 99 & 101 & ,342 &,- 868 \\
\hline & 4 & 63 & 99,71 & ,728 & ,092 & 100,00 & 98 & 101 &,- 625 & ,243 \\
\hline & 5 & 40 & 99,65 & ,580 & ,092 & 100,00 & 99 & 101 &,- 640 & 204 \\
\hline & 6 & 64 & 99,41 & ,495 & ,062 & 99,00 & 99 & 100 & $-1,908$ & ,391 \\
\hline & 7 & 57 & 99,88 & ,331 & ,044 & 100,00 & 99 & 100 & 3,703 & $-2,361$ \\
\hline & 8 & 34 & 99,65 & ,485 & ,083 & 100,00 & 99 & 100 & $-1,688$ &,- 644 \\
\hline & 9 & 37 & 99,89 & ,393 & ,065 & 100,00 & 99 & 101 & 3,149 & $-1,037$ \\
\hline & 10 & 46 & 99,91 & ,463 & ,068 & 100,00 & 99 & 101 & 1,787 &,- 340 \\
\hline & 11 & 27 & 100,15 & ,456 & ,088 & 100,00 & 99 & 101 & 1,528 & 661 \\
\hline & 12 & 23 & 99,74 & 1,251 & ,261 & 100,00 & 99 & 105 & 15,303 & 3,594 \\
\hline & 13 & 28 & 99,96 & 1,071 & ,202 & 100,00 & 99 & 105 & 19,440 & 3,973 \\
\hline & 14 & 35 & 99,89 & ,471 & ,080 & 100,00 & 99 & 101 & 1,551 &,- 406 \\
\hline & 15 & 21 & 99,62 & ,498 & 109 & 100,00 & 99 & 100 & $-1,913$ &,- 529 \\
\hline & Total & 673 & 99,84 & ,678 & ,026 & 100,00 & 98 & 105 & 10,133 & 1,653 \\
\hline \multirow[t]{8}{*}{ HC5 } & 1 & 94 & 95,40 & ,872 & ,090 & 96,00 & 90 & 96 & 15,133 & $-2,985$ \\
\hline & 2 & 56 & 95,23 & 1,362 & ,182 & 96,00 & 90 & 96 & 10,163 & $-3,127$ \\
\hline & 3 & 71 & 95,34 & ,559 & ,066 & 95,00 & 93 & 96 & 2,510 &,- 583 \\
\hline & 4 & 75 & 95,17 & ,381 & ,044 & 95,00 & 95 & 96 & 1,132 & 1,761 \\
\hline & 5 & 71 & 95,31 & ,466 & ,055 & 95,00 & 95 & 96 & $-1,332$ & 840 \\
\hline & 6 & 86 & 95,35 & ,479 &, 052 & 95,00 & 95 & 96 & $-1,621$ & ,646 \\
\hline & 7 & 81 & 95,42 & ,497 & ,055 & 95,00 & 95 & 96 & $-1,939$ & ,331 \\
\hline & 8 & 75 & 95,44 & ,500 & ,058 & 95,00 & 95 & 96 & $-1,993$ & ,247 \\
\hline
\end{tabular}


Bensimbon and Biondi: Financial Bubbles, Common Knowledge and Alternative Accounting Regimes: An Experimental Analysis of Artificial Spot Security Markets

(-Continued)

\begin{tabular}{|c|c|c|c|c|c|c|c|c|c|c|}
\hline Session & Period & $\mathrm{N}$ & Mean & $\begin{array}{c}\text { Std. } \\
\text { Deviation }\end{array}$ & $\begin{array}{l}\text { Std. Error } \\
\text { of Mean }\end{array}$ & Median & Minimum & Maximum & Kurtosis & Skewness \\
\hline & 9 & 83 & 95,47 & ,502 & ,055 & 95,00 & 95 & 96 & $-2,035$ & 123 \\
\hline & 10 & 83 & 95,42 & ,497 & ,055 & 95,00 & 95 & 96 & $-1,943$ & ,323 \\
\hline & 11 & 81 & 95,46 & ,501 & ,056 & 95,00 & 95 & 96 & $-2,019$ & 177 \\
\hline & 12 & 45 & 95,73 & ,447 & ,067 & 96,00 & 95 & 96 &,- 847 & $-1,092$ \\
\hline & 13 & 74 & 96,05 & ,546 & ,064 & 96,00 & 95 & 97 & ,467 & ,039 \\
\hline & 14 & 72 & 95,50 & ,504 & ,059 & 95,50 & 95 & 96 & $-2,058$ & ,000 \\
\hline & 15 & 63 & 95,56 & ,501 & ,063 & 96,00 & 95 & 96 & $-2,012$ &,- 229 \\
\hline & Total & 1110 & 95,45 & ,635 & ,019 & 95,00 & 90 & 97 & 18,096 & $-2,188$ \\
\hline
\end{tabular}


Appendix.Descriptive Statistics.Figures

FV1 Session Plot

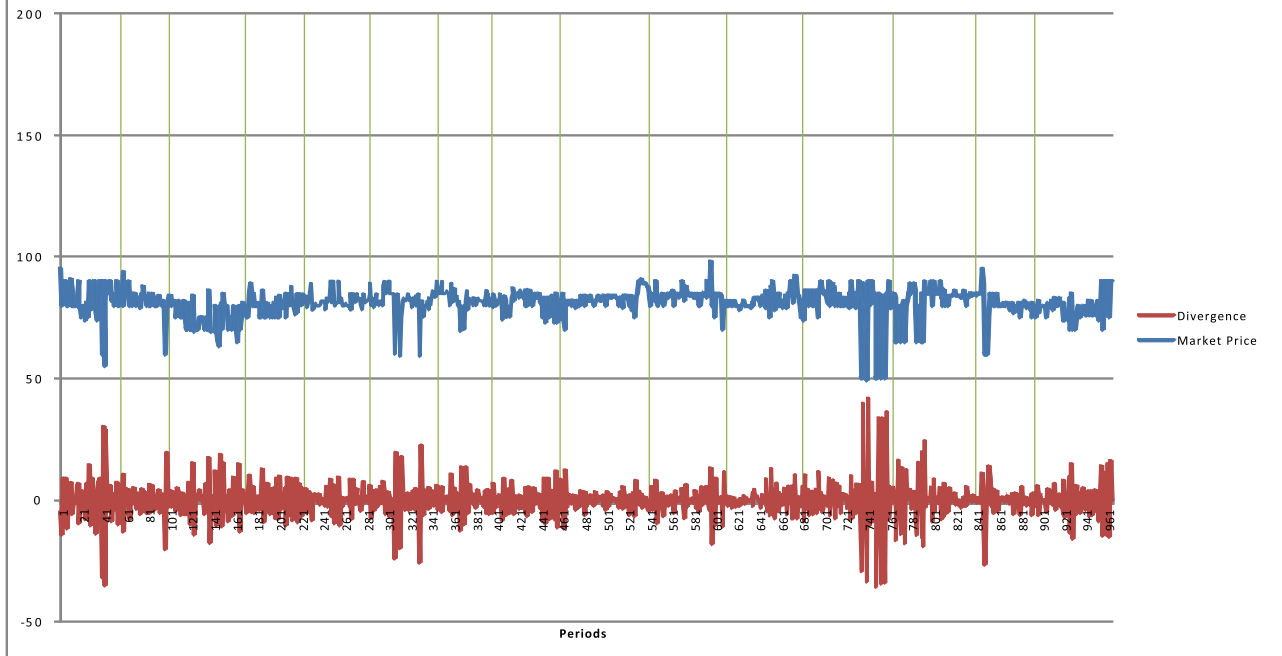

FV2 Session Plot

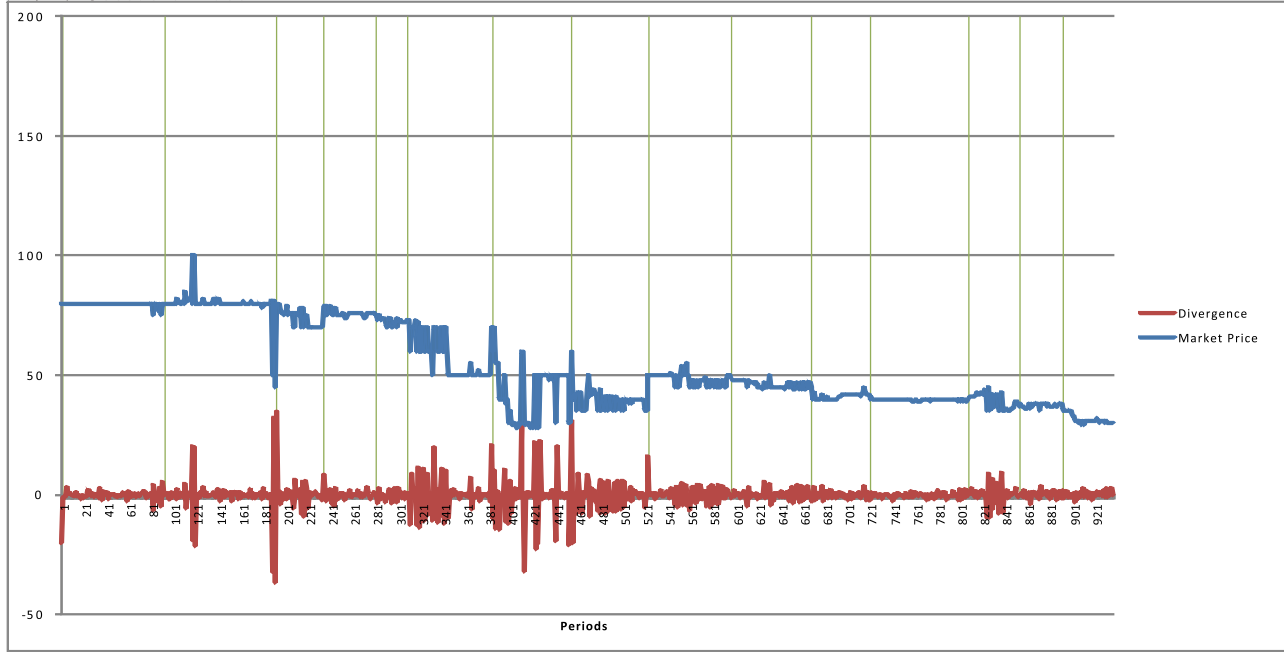


FV3 Session Plot

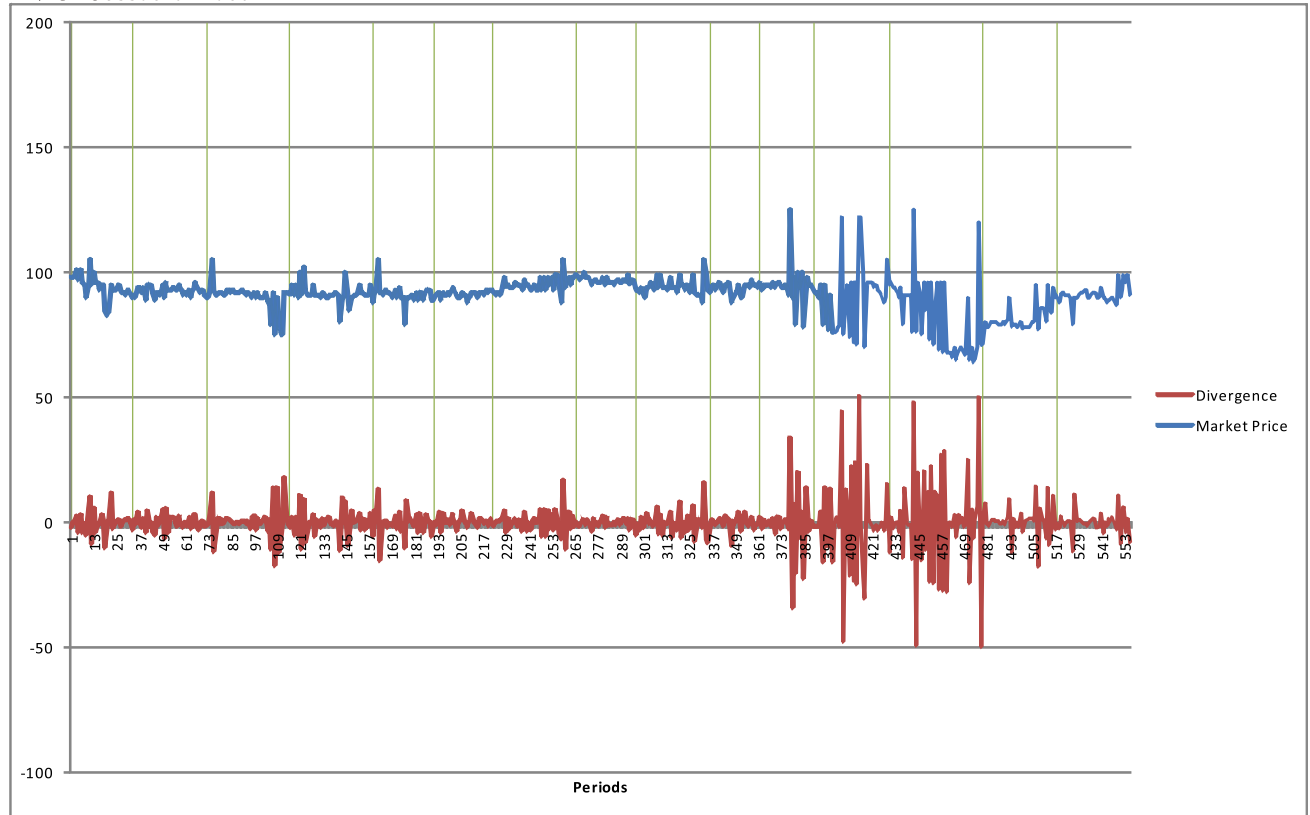

FV4 Session Plot

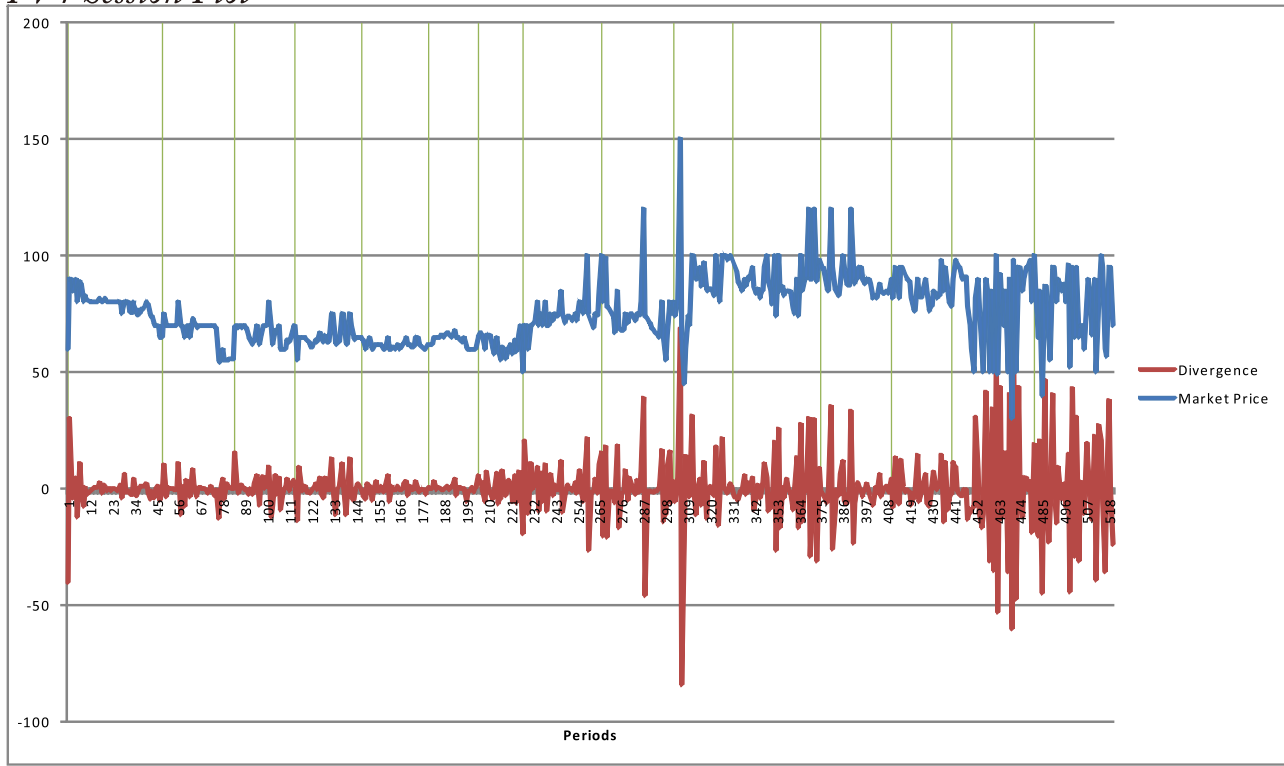


HC1 Session Plot

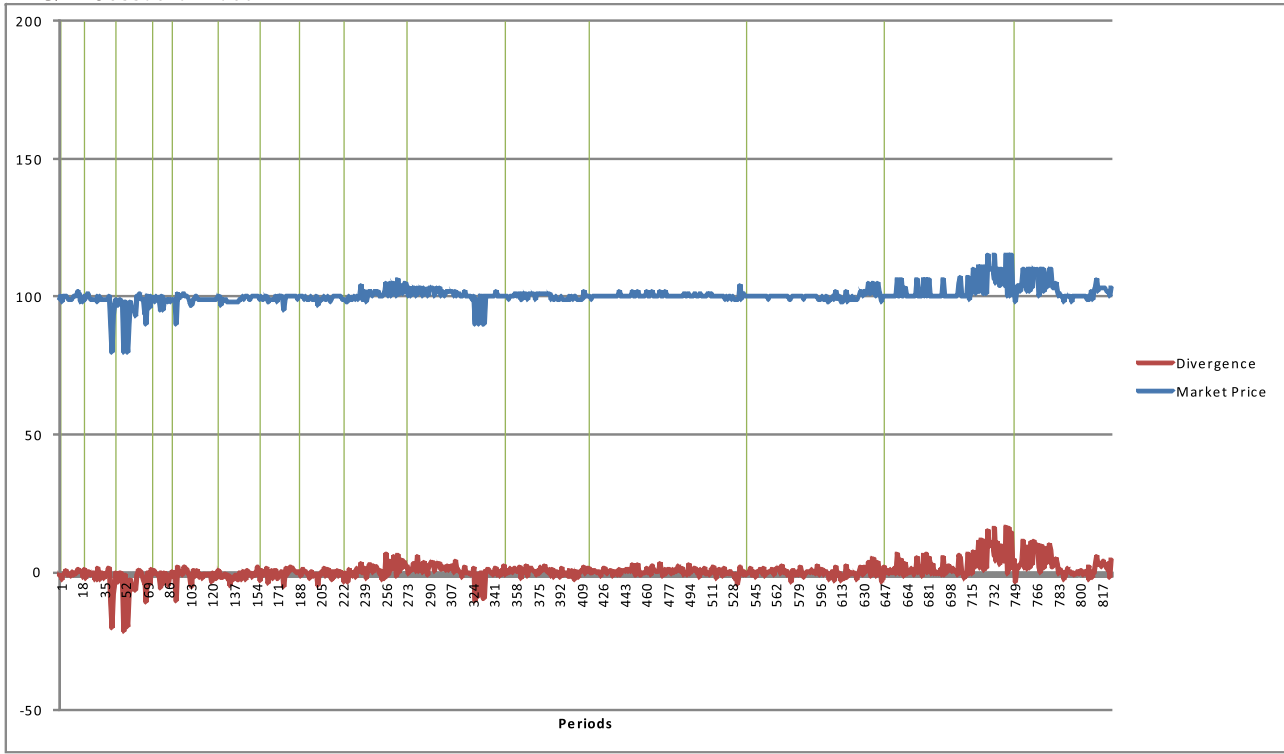

HC2 Session Plot

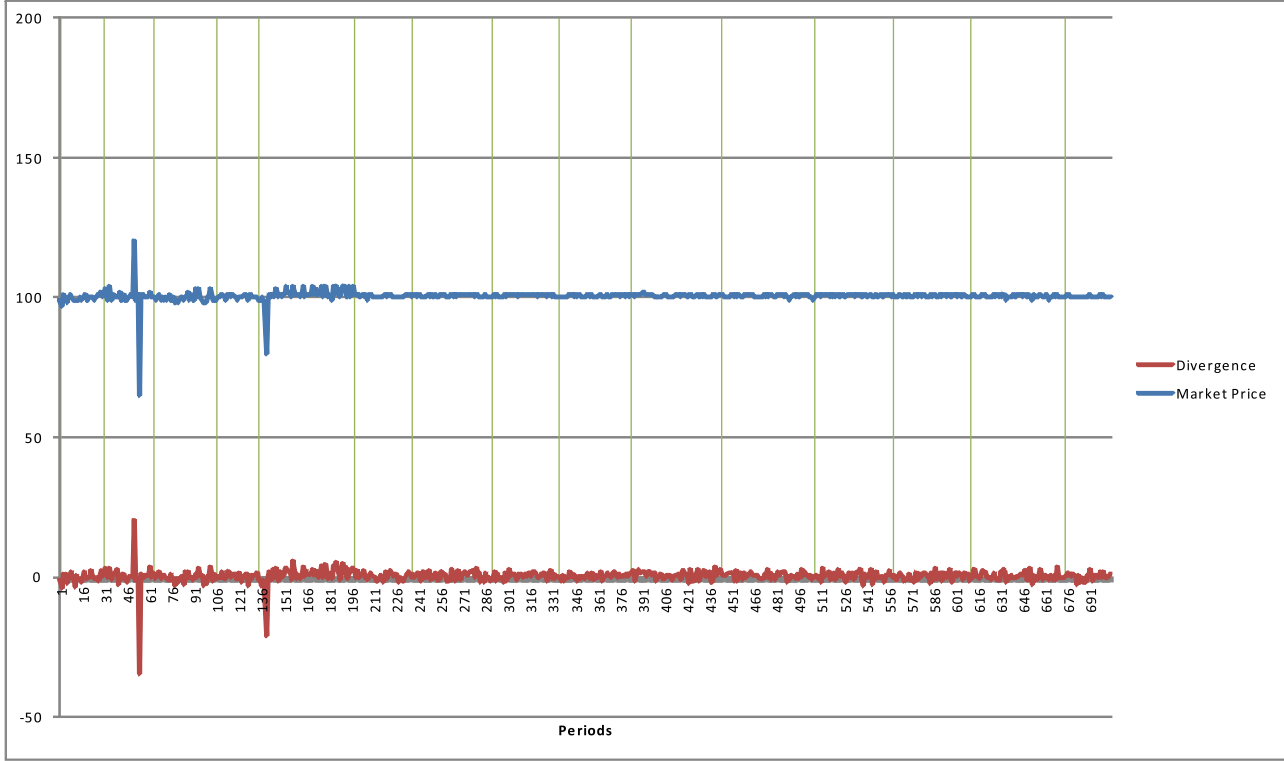


HC3 Session Plot

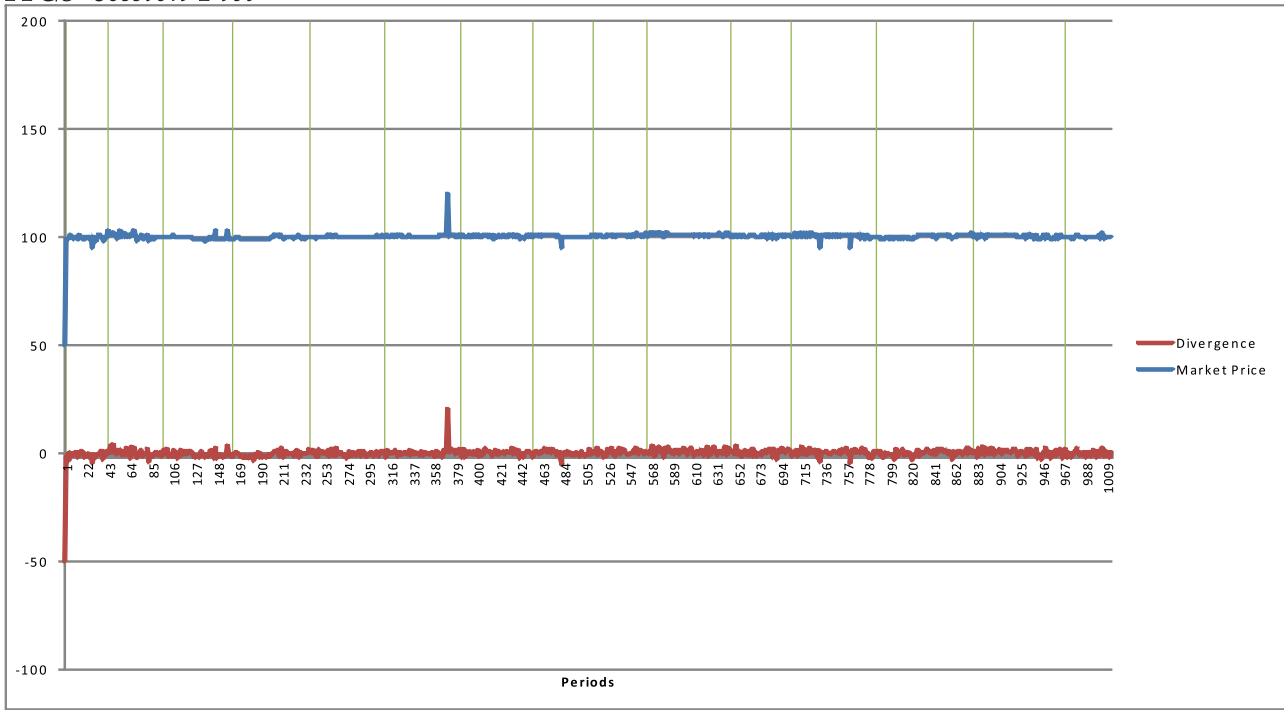

HC4 Session Plot

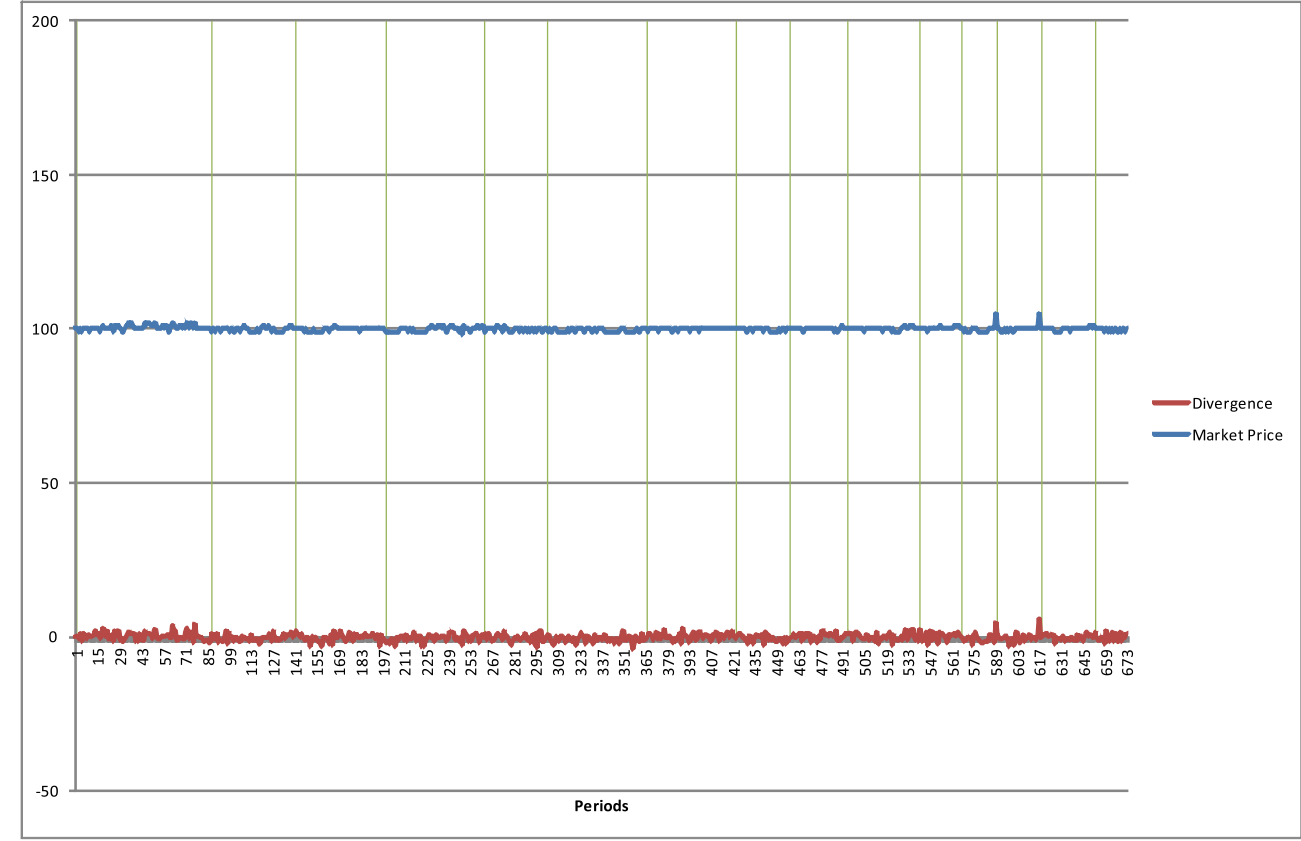


HC5 Session Plot

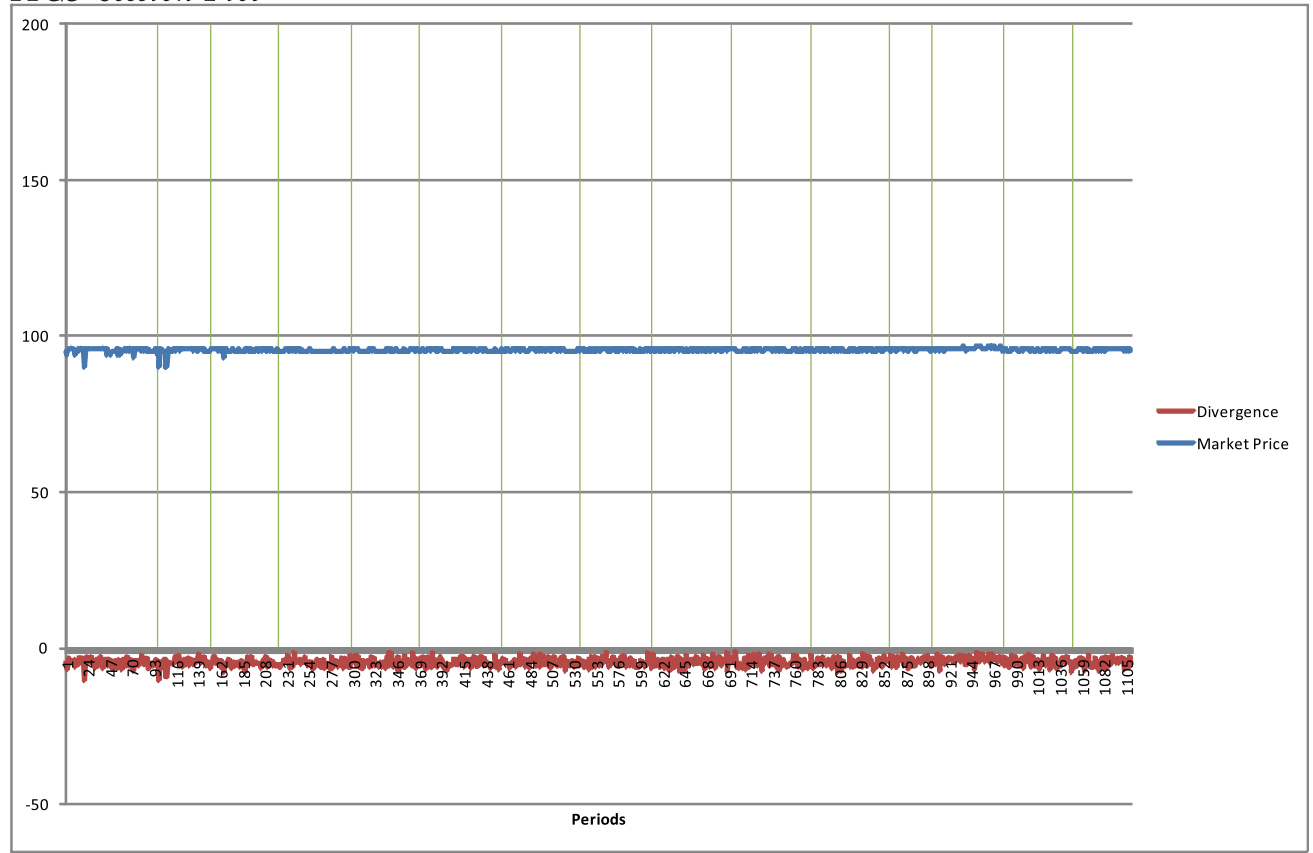


An Experimental Analysis of Artificial Spot Security Markets

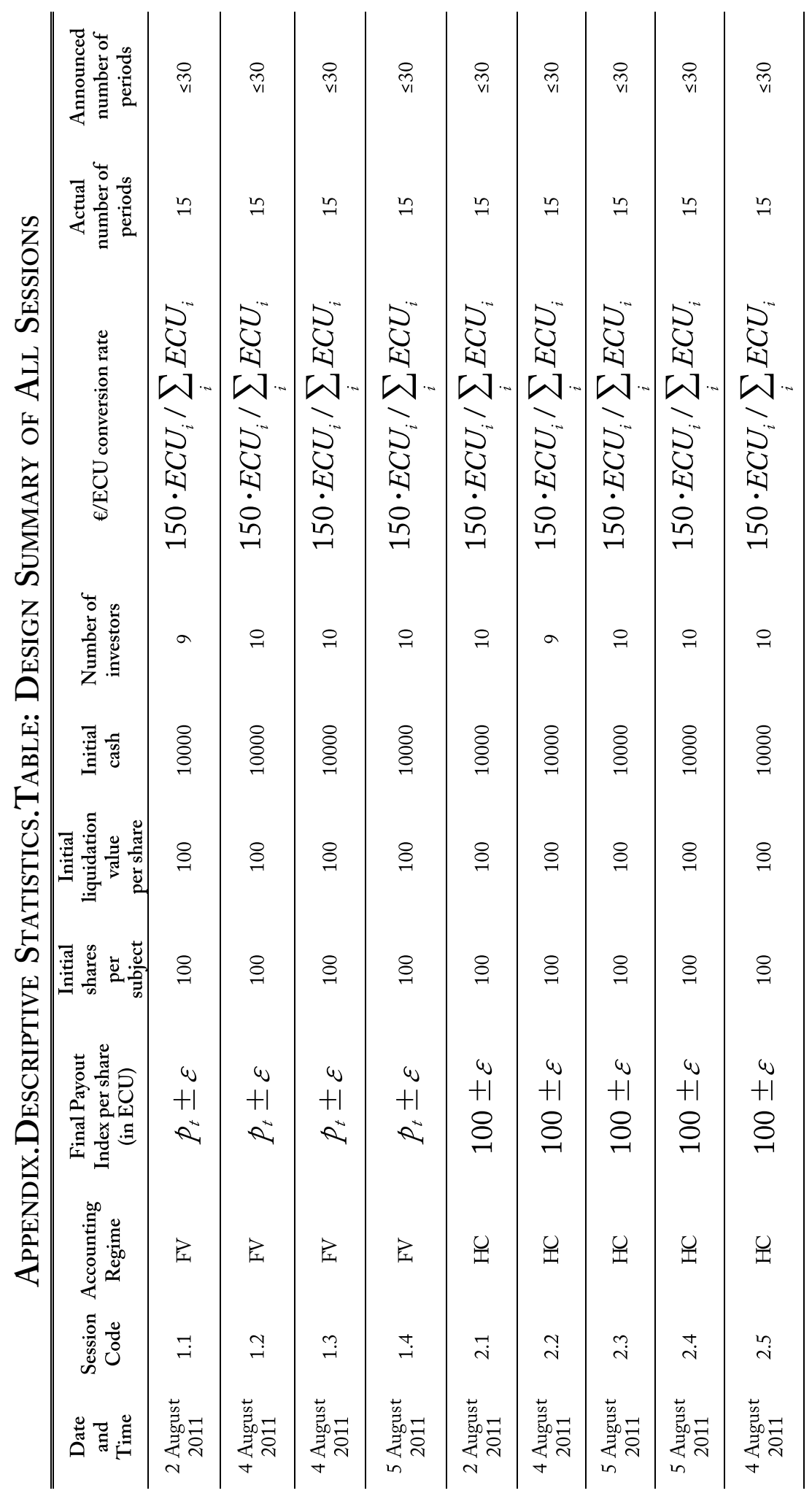




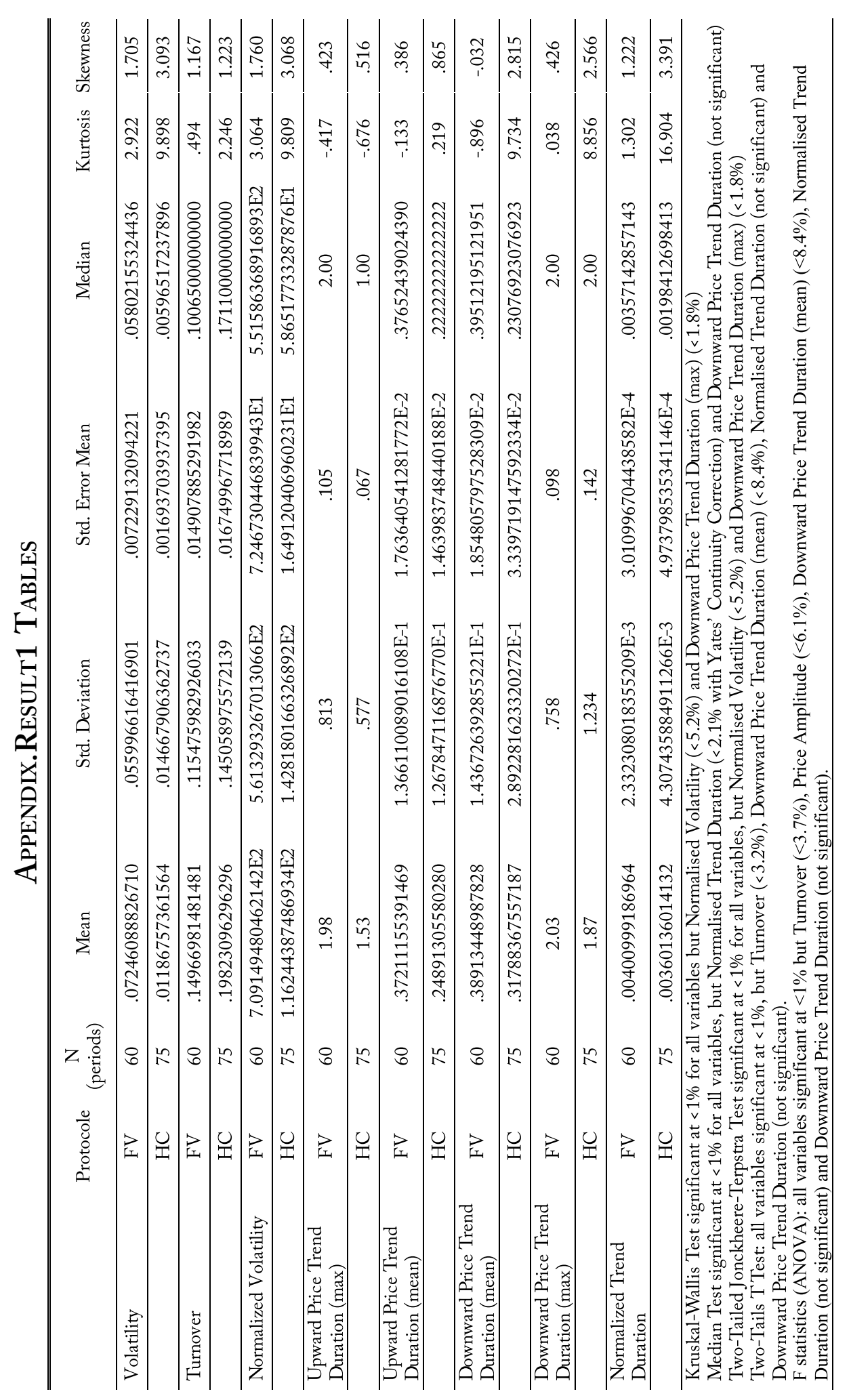



An Experimental Analysis of Artificial Spot Security Markets

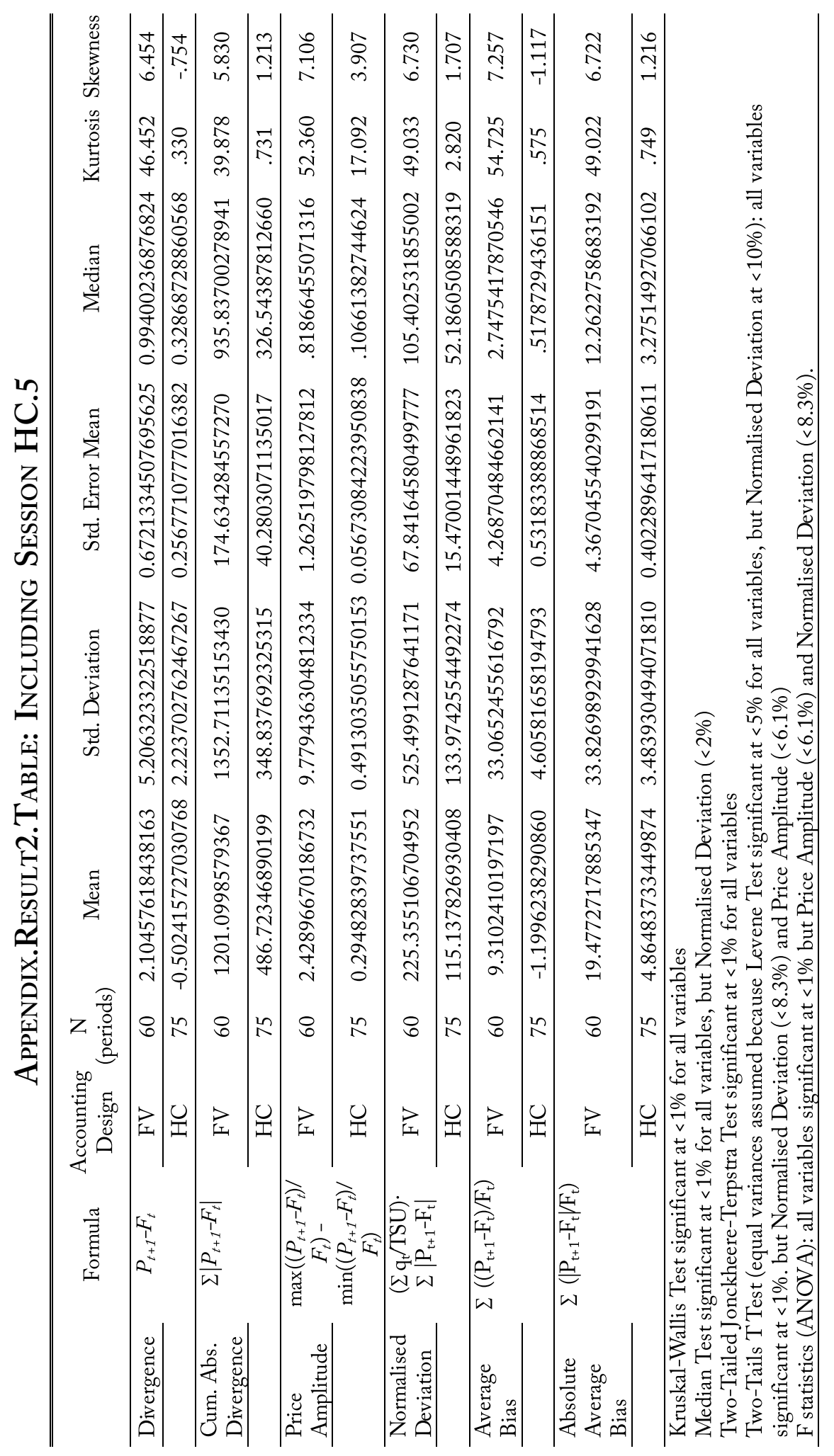




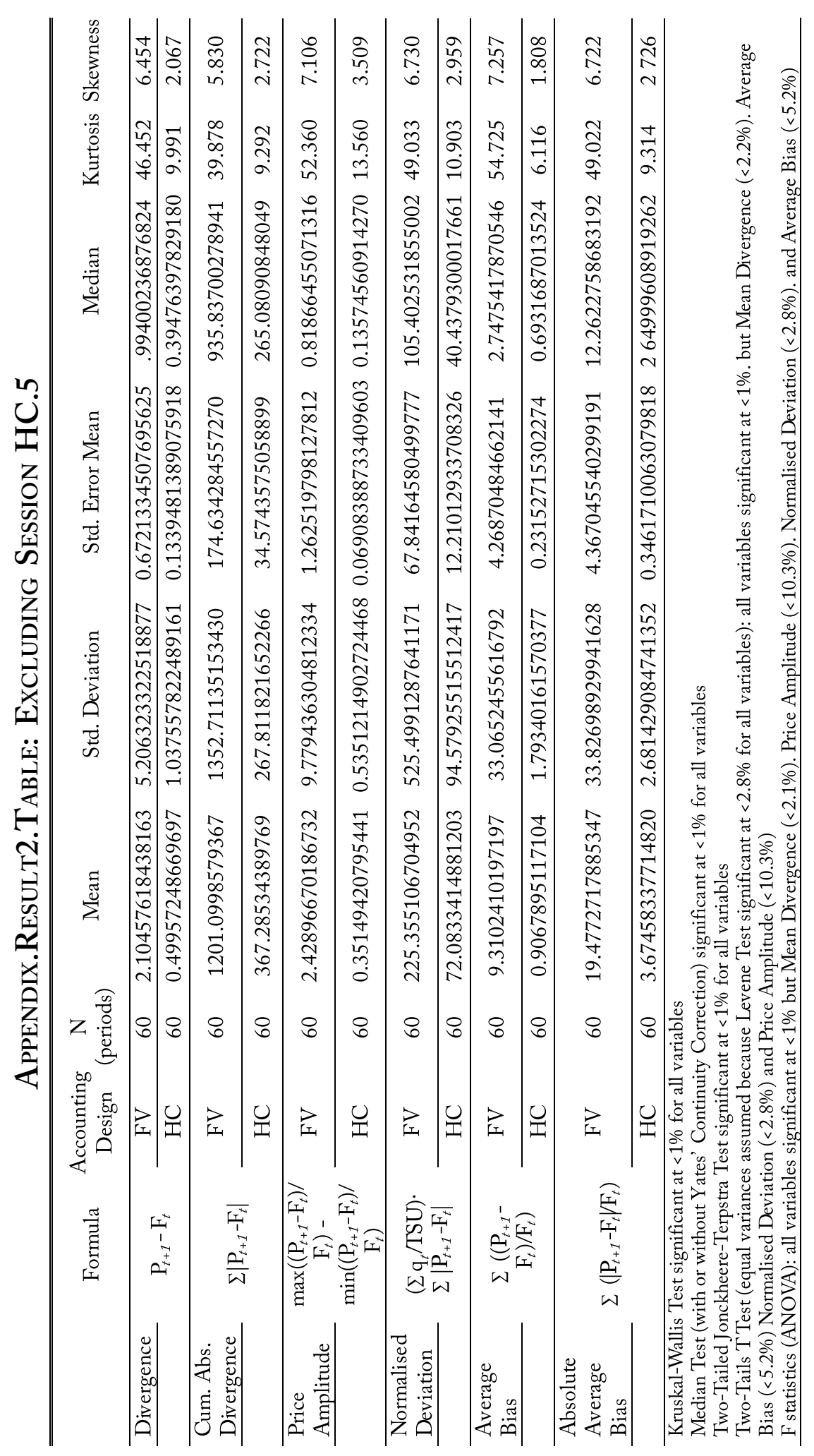




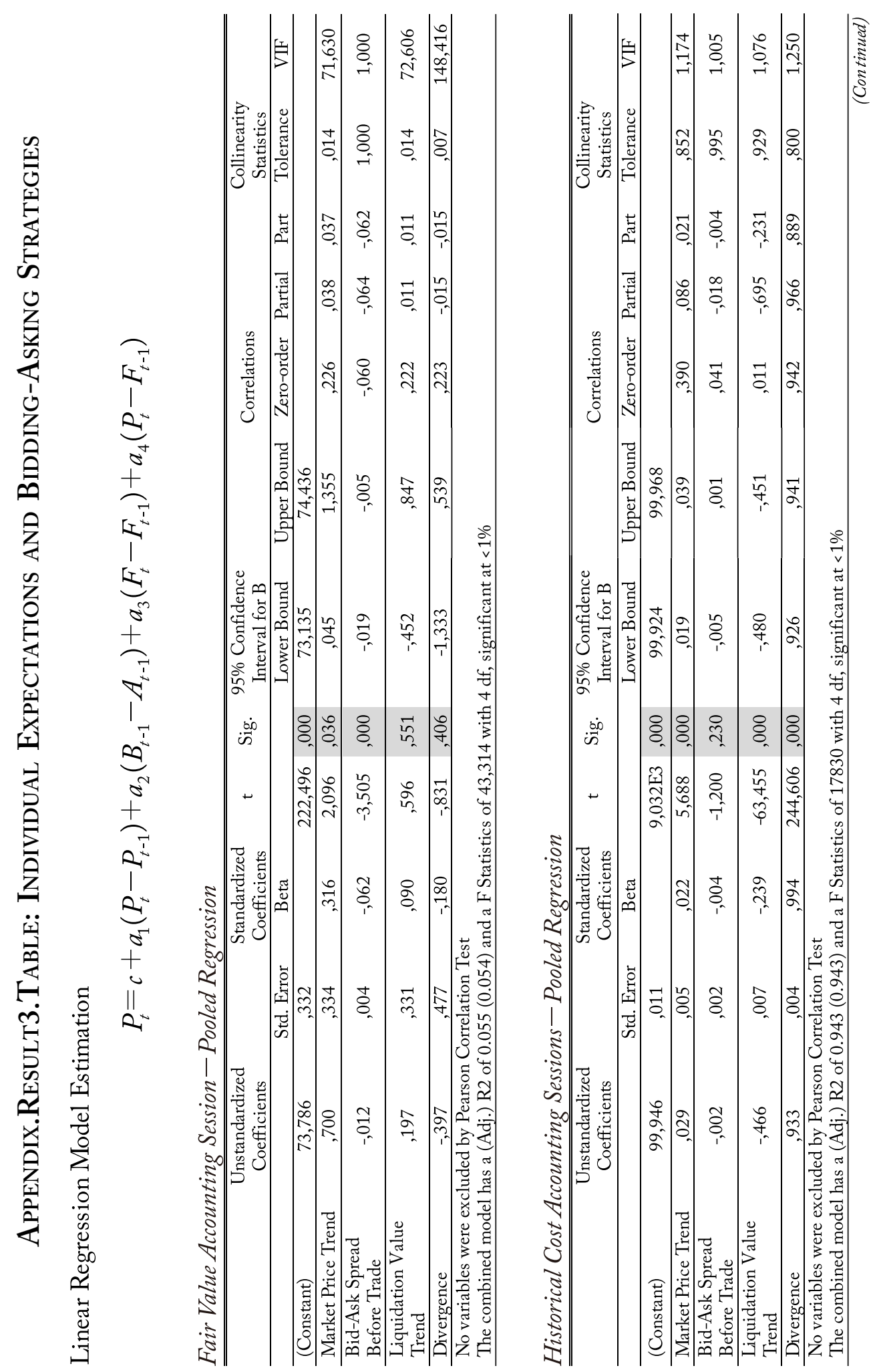




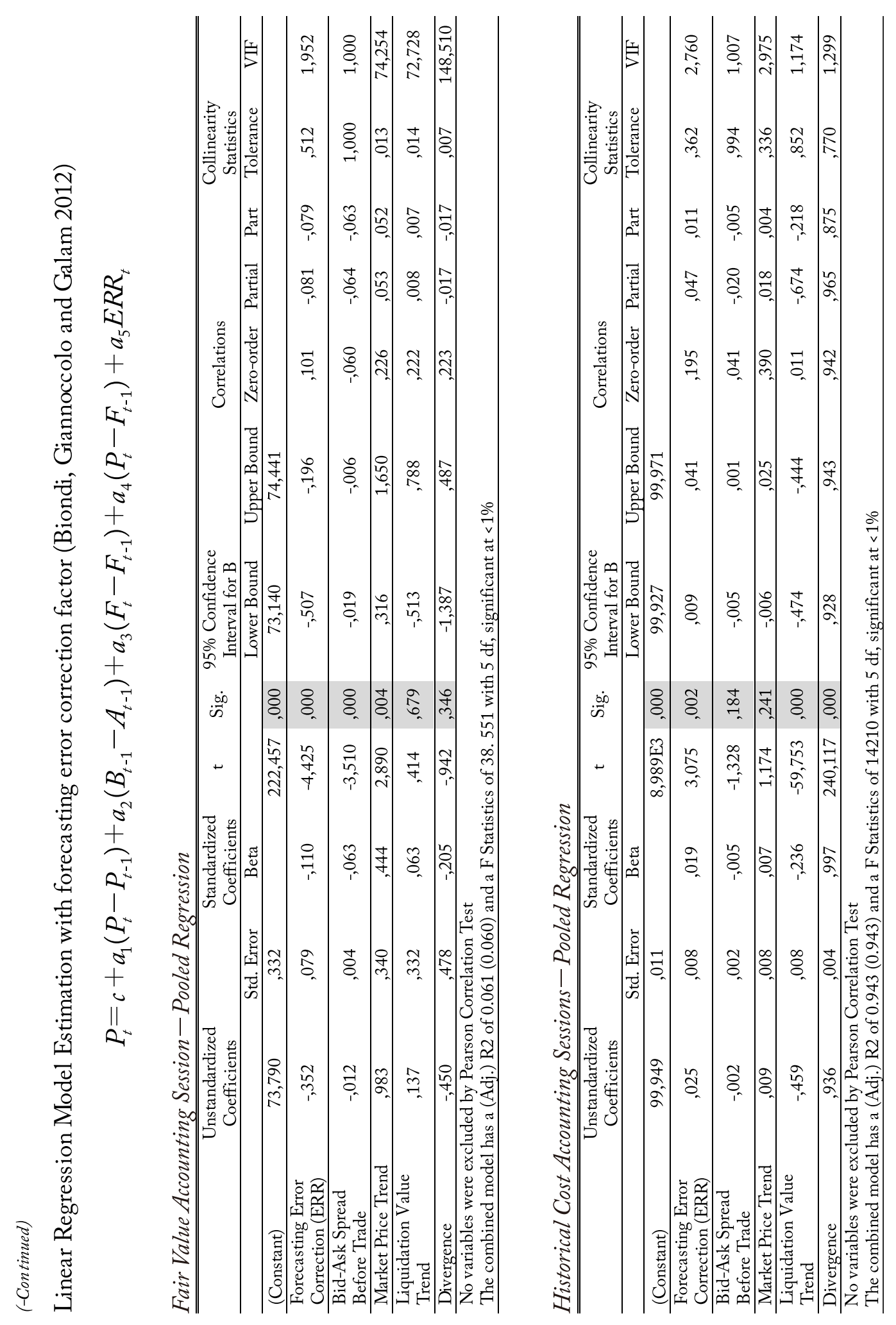


An Experimental Analysis of Artificial Spot Security Markets

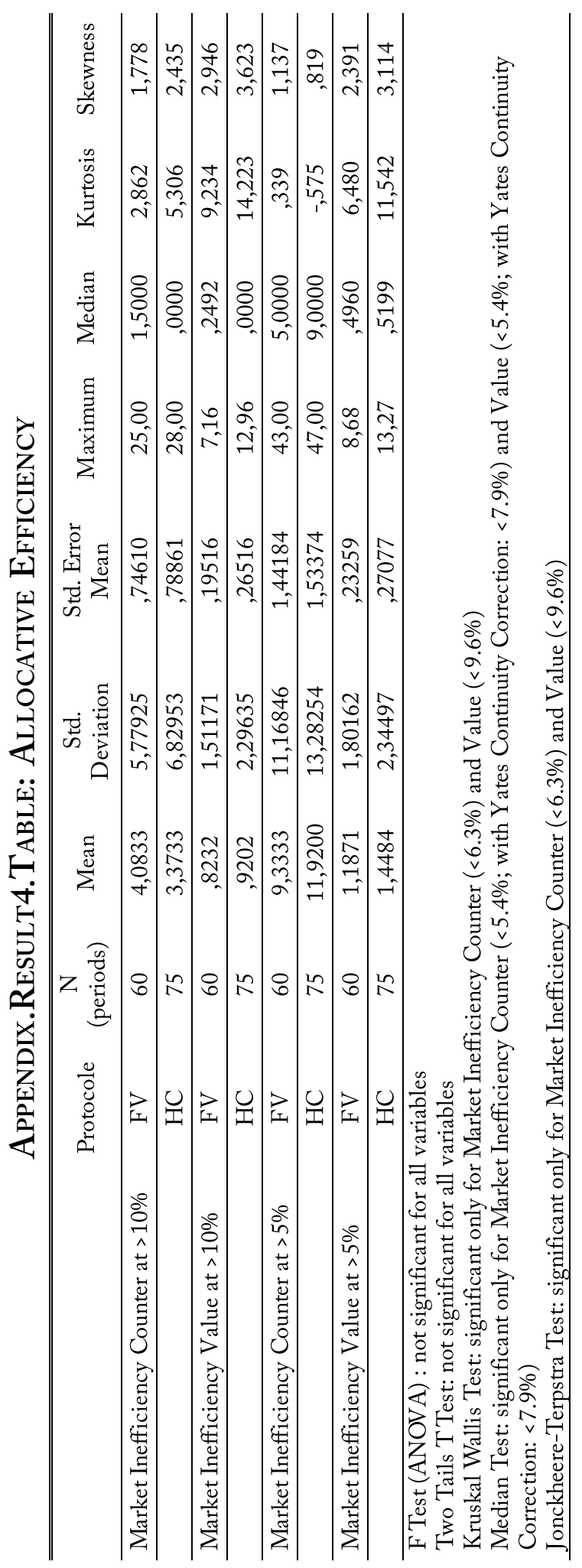




\section{Appendix.Result5.Figures}

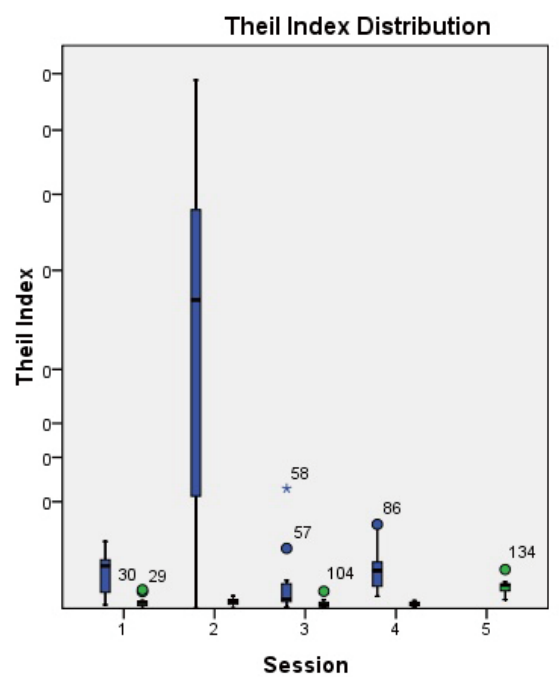

Theil index distribution by session for both protocoles (power scale)

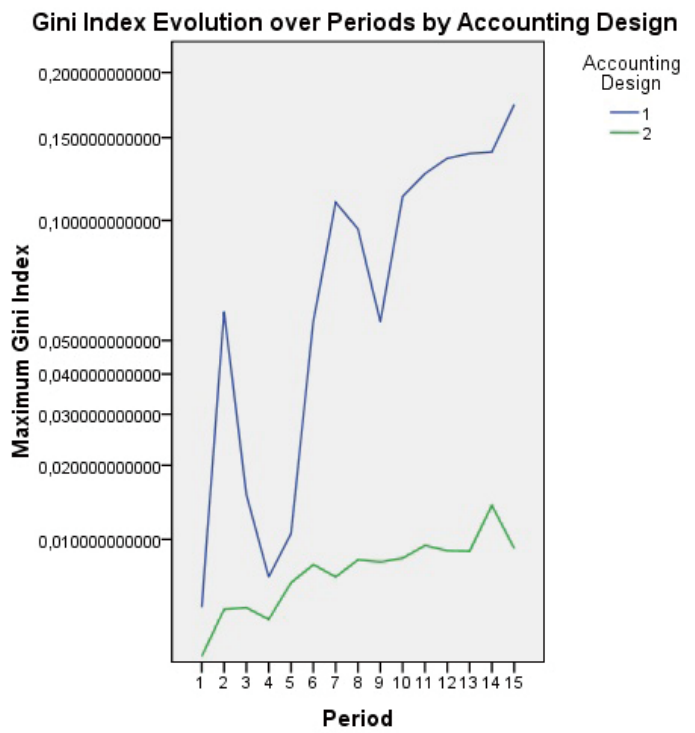

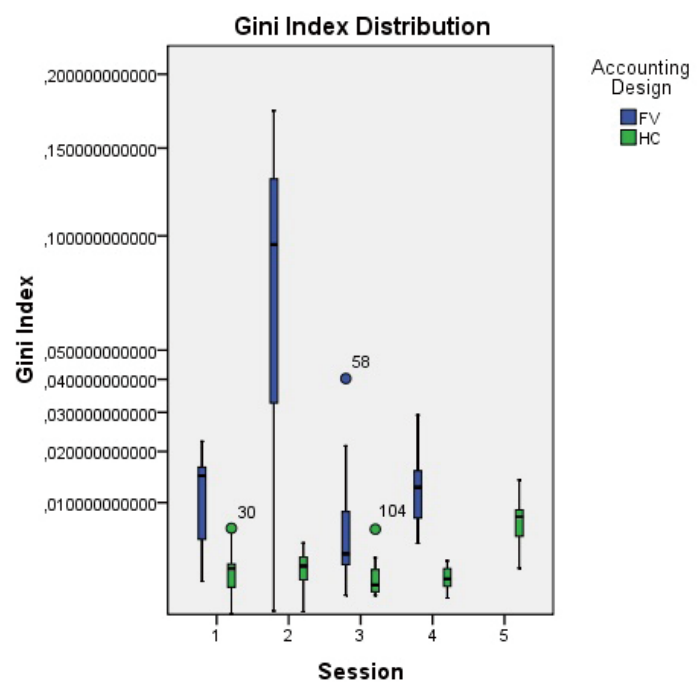

Theil Index Evolution over Periods by Accounting Design

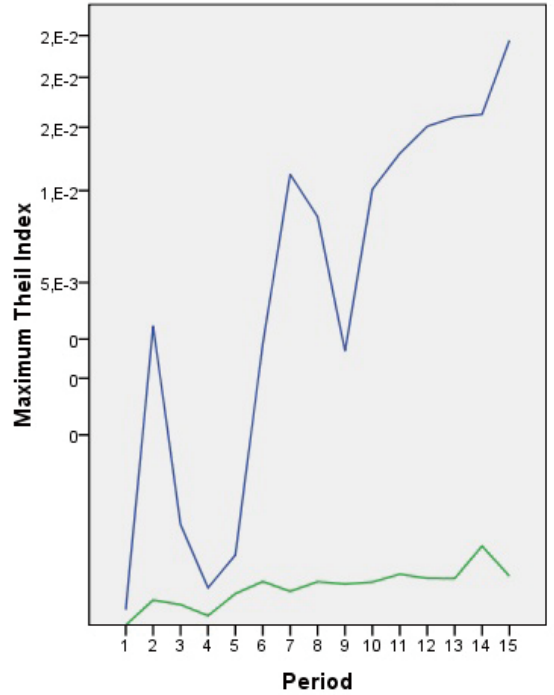

Accounting Design

$-1$ 


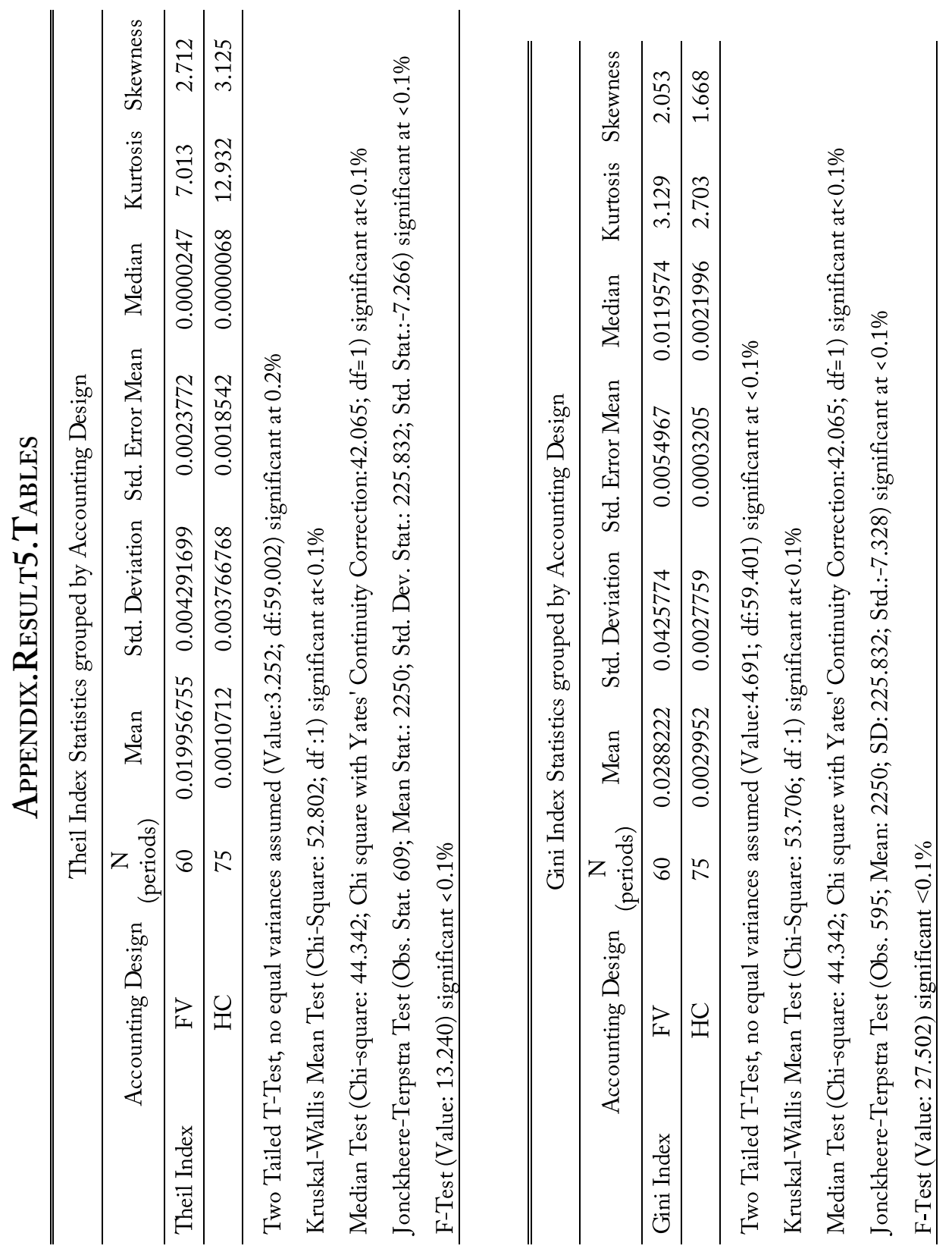




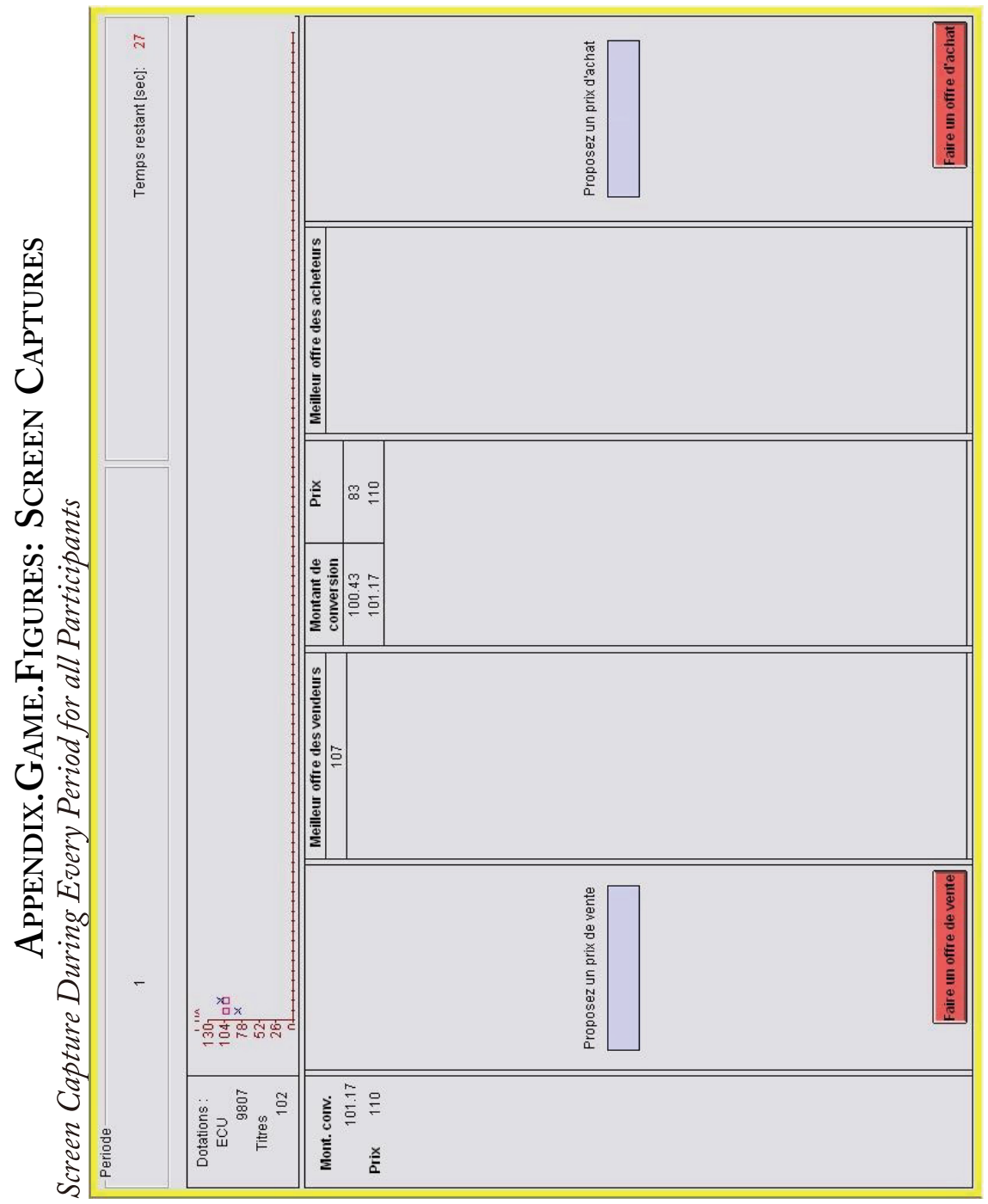



An Experimental Analysis of Artificial Spot Security Markets

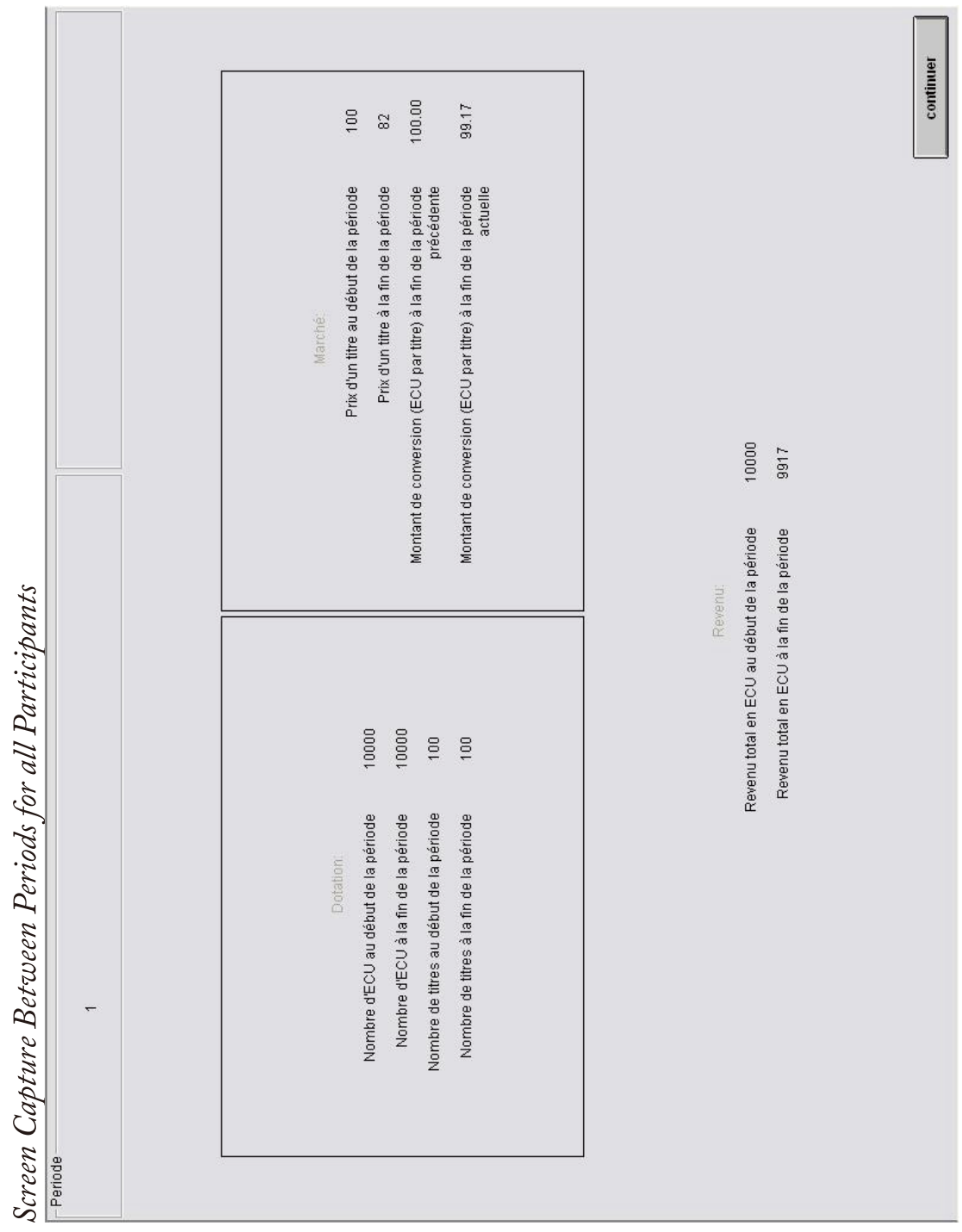

 


\section{Appendix.Game: Instructions Sheet for All Participants}

This experience concerns investment decision-making. These instructions are simple and more you take good decisions, more you will gain points. Your purpose is then to accumulate a maximum amount of points before the end of the session. The total of your points will be then converted in euro and paid cash: your earnings may range between 0 and 150 euro. More points you earn, more euros you will receive at the end of the session.

You cannot talk to other participants and you should follow the instructions given by experimenters. Any breach of this rule may involve a reduction of your points.

The session consists of a financial market to trade securities. You can trade securities. As an investor, you can buy and/or sell these securities at current proposed prices.

At the beginning of the session, you have:

- An initial endowment of 100 securities. You can sell these securities or keep them indefinitely at will, until the end of the session.

- An initial endowment of 10000 points. You can utilize these points to buy securities or keep them indefinitely at will, until the end of the session.

\section{Security Trading}

The session consists of several exchange periods of three minutes each, with a short interruption between each period. Buying a security implies its payment in points at its offered price. After every purchase, your endowment of points will be reduced by the price paid for the security. Furthermore, you can also sell the securities you hold. Every sale will increase your endowment of points by the price exchanged for the security.

\section{The conversion amount of the securities}

The number of periods may be equal or less than thirty (30), but it is likely to be less than its maximum duration. The experience may stop at the end of whatever period, and your securities will be then converted in points. The initial conversion amount is 100 point for each security; it may vary over time and will have been continuously showed on the screen of all the participants during the whole duration of the session.

\section{Your final income}

Therefore, your final income (= number of points accumulated) depends on two sources:

- Profits and losses realized through your trading activity,

- The conversion of your titles at the conversion amount.

On this basis, your income at the end of the session will be determined as follows: 
Final income $=\left(\right.$ conversion amount ${ }^{*}$ number of held securities $)+$ final endowment of points - initial reserve of points (that is, 10000 points)

The conversion amount for computing the final income is the last amount announced on all screens.

(Literal translation from French) 